\title{
1 Co-option of the Limb Patterning Program in Cephalopod Lens Development
}

3 Stephanie Neal*, Kyle J. McCulloch*, Francesca Napoli, Christina M. Daly, James H. Coleman,

4 Kristen M. Koenig

$5 \quad *$ These authors contributed equally to this work

$7 \quad$ Affiliations

8 John Harvard Distinguished Science Fellowship Program, Harvard University, Cambridge, MA

902138 USA.

Department of Organismic and Evolutionary Biology, Harvard University, Cambridge, MA 02138

12 USA

13

14 Corresponding author email address

15 kmkoenig@,fas.harvard.edu

16

17 Keywords: Cephalopod, lens, Distal-less, SP6-9, co-option, Eye evolution, limb outgrowth 


\section{Abstract}

20 Across the Metazoa, similar genetic programs are found in the development of analogous,

21 independently evolved, morphological features. The functional significance of this reuse and the

22 underlying mechanisms of co-option remain unclear. Here we identify the co-option of the

23 canonical bilaterian limb pattering program redeployed during cephalopod lens development, a

24 functionally unrelated structure. We show radial expression of transcription factors SP6-9/sp1,

25 Dlx/dll, Pbx/exd, Meis/hth, and a Prdl homolog in the squid Doryteuthis pealeii, similar to

26 expression required in Drosophila limb development. We assess the role of Wnt signaling in the

27 cephalopod lens, a positive regulator in the developing limb, and find the regulatory relationship

28 reversed, with ectopic Wnt signaling leading to lens loss. This regulatory divergence suggests that

29 duplication of SP6-9 in cephalopods may mediate this co-option. These results suggest that the

30 limb network does not exclusively pattern appendage outgrowth but is performing a more universal

31 developmental function: radial patterning. 


\section{INTRODUCTION}

In the Metazoa, homologous networks of transcription factors are necessary for the

34 development of some analogous structures in distantly related taxa. The limb patterning program

35 is an example of this developmental process homology (Shubin et al., 1997; Erwin \& Davidson,

36 2002; Pueyo \& Couso, 2005). The limb program was first identified in the development of the

37 proximal-distal axis of the Drosophila leg. The transcription factor SP6-9/sp1 is upstream of other program members, Dlx/dll, Pbx/exd, Meis/hth, Dac and Arx/ar, each required for patterning specific regions of limb outgrowth (Panganiban et al., 1994; Panganiban et al., 1997; Dong et al., 2001, Dong et al., 2002; Peuyo \& Couso, 2005; Estella et al., 2012; Campbell \& Tomlinson, 1998). This network is necessary in both vertebrate and cephalopod limb development and is expressed in a similar proximodistal pattern in a diversity of outgrowths (Panganiban et al., 1997; Shubin et al., 1997; Maas \& Bei, 1997; Mercader et al., 1999; Panganiban \& Rubenstein, 2002; Prpic, 2003; Angelini \& Kaufman, 2005; Pueyo \& Couso, 2005; Shubin et al., 2009; Moczek \& Rose, 2009; Capellini et al. 2011; Lapan \& Reddien, 2011; Ibarretxe et al., 2012; Grimmel et al., 2016; SanzNavarro et al., 2019; Ramanathan et al. 2018; Setton \& Sharma; 2018; Tarazona et al., 2019; Prpic, 2019). This suggests that, although each appendage is not homologous, an outgrowth program may have been present in the ancestor. Current fossil evidence and the prevalence of limbless taxa does not support an ancestor with appendages and therefore the network's ancestral function remains unclear (Shubin et al., 1997; Erwin \& Davidson, 2002; Pueyo \& Couso, 2005). Many alternative hypotheses have been proposed, including an ancestral role in the nervous system, body axis formation and radial patterning (Minelli, 2000; Pueyo \& Couso, 2005; Lemons et al. 2010; McDougall et al., 2011; Plavicki et al., 2016; Carroll et al., 1994; Erwin \& Davidson, 2002). To understand the nature of this homology and how these co-option events occur, experiments with better sampling across the phylogeny of animals and greater diversity of developmental context 56 are required.

Recent work identified a duplication of SP6-9 in cephalopods (McCulloch and Koenig, 2020). Both paralogs are expressed in the developing limb in the squid Doryteuthis pealeii, while one paralog, $D p S P 6-9 a$, shows unique expression in the lens-making cells during eye development

60 (McCulloch and Koenig, 2020). With SP6-9 a known regulator in the limb patterning program,

61 this new domain of expression could result in the co-option of the program in the cephalopod eye,

62 providing a useful heterologous developmental context to better understand the network's 63 function. 
The image-forming eye is a classic example of biological complexity and the lens is a requisite innovation in all high-resolution visual systems (Darwin, 1859; Arendt, 2009; Dakin, 1928; Walls, 1939; Koenig \& Gross, 2020; Nilsson, 2013; Jonasova \& Kozmik, 2008). Cephalopods have a single-chambered eye, morphologically convergent with the vertebrate eye, composed of a cup shaped retina and a single refractive lens (Packard, 1972). Here we perform the first in-depth molecular description of lens development in the squid Doryteuthis pealeii, we identify spaciotemporal expression of the limb patterning program in the developing eye and lens, and we demonstrate a negative regulatory role of canonical Wnt signaling upstream of the

72 program.

\section{RESULTS AND DISCUSSION}

\section{Cephalopod Lentigenic Cell Differentiation and Early Anterior Segment Heterogeneity}

The anterior of the cephalopod eye, or the anterior segment, is composed primarily of lens generating cells (lentigenic cells) (Williams, 1909; Arnold, 1967; Brahma, 1978). Lentigenic cells are arranged circumferentially around the developing lens and extend long cellular processes, fusing into plates to form the lens (Figure 1A) (Meinertzhagen, 1990; Williams, 1909; Arnold, 1965; Arnold, 1967; West et al., 1995). We identified the first evidence of differentiated lentigenic cells starting at late stage 21 , using a previously described nuclear morphology, unique to one of the three lentigenic cell types (LC2) (Figure 1B) (Arnold, 1967; West et al., 1995; Koenig et al., 2016). The number of LC2 cells continues to grow until reaching pre-hatching stage (Stage 29). We performed staged in situ hybridization for a homolog of DpS-Crystallin, the most abundant family of proteins in the cephalopod lens (Chiou, 1984; West et al., 1994) (Supplemental Figure 1). The first evidence of expression corresponds to changes in nuclear morphology at stage 21 (Figure 1C).

We sought to understand the molecular heterogeneity of cells in the early developing anterior segment, of which nothing is currently known. Using previously published candidates and RNA-seq data, we performed in situ hybridization screens at stage 23 to identify unique cell populations (Koenig et al., 2016; Ogura et al., 2013). We find DpSix3/6 at stage 23 expressed in the anterior segment in the distal cells that make a central cup $(c c)$, as well as a marginal population of cells in the most proximal tissue ( $\mathrm{pm}$ ) (Figure 2B' '). The proximal central cells lacking DpSix $3 / 6$ expression correspond to the LC2 population (Figure 2A" \&B'"). Asymmetry along the animal anterior-posterior axis in the eye is also apparent, with enrichment on the anterior side of the animal (Figure 2B'"). We also find the gene $D p L h x 1 / 5$, expressed in a distal-marginal population of cells 
97 in the anterior segment $(d m)$, and excluded from the distal central cup cells (cc) (Figure 2C',).

98 Together these genes show distinct populations of cells present early in development and provide

99 a helpful molecular map of the anterior segment tissue at this time point: central cup cells $(c c)$,

100 LC2 cells (lc2), proximal-marginal cells $(\mathrm{pm})$, and distal-marginal cells $(\mathrm{dm})$ (Figure 2) .

\section{Proximal-Distal Limb Patterning Genes in the Anterior Segment of the Cephalopod}

To assess whether genes involved in appendage patterning may be required for cephalopod lens development, we identified and performed in situ hybridization for the genes $\mathrm{Dlx}, \mathrm{Pbx}$, Meis, and Dac at stage 21 and 23 (Figure 2, Supplemental Figure 2). All genes were clearly expressed in the developing anterior segment and lentigenic cells with the exception of DpDac (Figure 2EG, Supplemental Figure 2I-2J'). We find $D p D l x$ and $D p S P 6-9 a$ have overlapping expression, in the central cup cells (cc) and all proximal cells (LC2 and pm) (Figure 2D-E','). DpPbx and DpMeis are both broadly expressed in the anterior segment during lens development, with $D p P b x$ excluded from the LC2 cells (Figure 2F', \& 2G'').

It is known that the transcription factor aristaless is necessary for the most distal tip of the

112 Drosophila limb in the limb program (Campbell and Tomlinson, 1998). The evolutionary 113 relationship of Prd-like homologs (Arx/Aristaless, Alx/Aristaless-like, Rx/Retinal Homeobox and $114 \mathrm{Hbn} /$ Homeobrain) is ambiguous across species (Schiemann et al., 2017). We identified three 115 candidate Prd-like genes in D. pealeii and performed in situ hybridization for all three homologs, 116 DpHbn, DpPrdl-1 and DpPrdl-2 (Supplemental Figure 2K, L) (Koenig et al, 2016). DpHbn is 117 expressed in the anterior segment in the distal central cup cells (cc) while DpPrdl-1 and DpPrdl1182 are excluded from the eye (Figure 2H' and Supplemental Figure 2C, C', K and L). DpHbn's 119 central, distal expression recapitulates aristaless expression in the developing Drosophila limb.

120 Our data show that the majority of the proximal-distal patterning genes in the developing 121 limb, including SP6-9, Dlx, Meis, Pbx, as well as the Prd-like homolog, Hbn, show expression in 122 concentric and overlapping cell populations surrounding the developing lens in the squid (Figure 123 2). This pattern of expression is strikingly similar to the bullseye-like pattern of expression of these 124 genes in the developing Drosophila limb imaginal disc and suggests a co-option of this regulatory 125 program for a new function: patterning the cephalopod anterior segment and lens (Angelini \& 126 Kaufman, 2005). 
The duplication of SP6-9 in cephalopods provides a substrate for the evolution of cisregulation, which could result in novel expression of the limb patterning program in the cephalopod lens. In appendage outgrowth, active Wnt signaling is upstream of the expression of SP6-9 (Cohen, 1990; Estella et al., 2003). To assess whether Wnt may be acting upstream in the

133 cephalopod anterior segment or whether novel regulatory mechanisms may be at play, we

134 performed in situ hybridization for members of the Wnt signaling pathway at stage 21 and stage

13523 (Figure 3, Supplemental Figure 3). We were interested in identifying cells in the anterior

136 segment or in adjacent tissue that may be a source of the Wnt morphogen. We performed in situ

137 hybridization for seven Wnt homologs, with most Wnt genes expressed in the retina (Figure 3A',

138 3C', 3D-G). DpWnt8, DpWnt11 and DpProtostome-specific Wnt show the most robust retinal 139 expression $\left(3 \mathrm{~A}^{\prime}, 3 \mathrm{~F} \& 3 \mathrm{G}\right)$ and $D p W n t 7$ is the only Wnt expressed in the anterior segment (Figure

140 3C). DpWnt6 showed no evidence of expression in the developing eye (data not shown). These data support the hypothesis that Wnt signals emanating from neighboring tissues could regulate anterior segment development.

143 To identify cells with potential active Wnt signaling, we analyzed the expression of $\mathrm{Fz}$ 144 genes, which encode a family of Wnt receptors. We find that $D p F z$ receptors are expressed broadly 145 throughout the embryo. A subset of these (e.g. $D p F z 1 / 2 / 7, D p F z 4$, and $D p F z 5 / 8$ ) are expressed in 146 the majority of cells in the anterior segment, while others, like $D p F z 9 / 10$, are excluded from the 147 anterior segment (Figure 3H-K, Supplemental Figure 3). On close examination we find that $D p F z 5 / 8$ is excluded asymmetrically in the anterior segment and may be important for anterior149 posterior patterning (Figure 3J' \& J') $. D p F z 1 / 2 / 7$ is excluded from the distal-marginal cells and 150 central cup cells and interestingly, the central cup cells lacking $D p F z 1 / 2 / 7$ are those that express 151 all the limb patterning program genes (Figure 3K'\&K'”). These data suggested that the exclusion 152 of active Wnt signaling may be important in the cephalopod anterior segment, supporting a 153 potential negative regulatory role for Wnt signaling.

\section{Ectopic Wnt Activation Leads to the Loss of the Lens}

To assess the hypothesis that Wnt signaling is playing a negative regulatory role in anterior 157 segment development, we utilized well-characterized pharmacological compounds that act as 158 agonists of the Wnt pathway (Hedgepeth et al. 1997; Klein \& Melton; Sato et al., 2004). We 159 empirically determined a working concentration of both $\mathrm{LiCl}(0.15 \mathrm{M})$ and CHIR99021 (250um).

160 We bathed embryos in the compound or vehicle control for 24 hours at stage 21, the onset of 161 lentigenic cell differentiation, and immediately fixed thereafter. Embryos were sectioned and 
assessed for phenotypes. Stage 21 control embryos show a thickened anterior segment, identifiable

163 lentigenic cells, and small lens primordia (Figure 3L). LiCl-treated stage 21 embryos show a

164 complete absence of lens formation: No anterior segment thickening, lentigenic cells, or lens tissue. These data suggest that ectopic Wnt pathway activation inhibits lens and anterior segment development (Figure 3L', Supplemental Figure 4A). CHIR99021 treatment showed similar phenotypes (Supplemental Figure 4A). We assessed LiCl treated and control animals for cell death and find little difference between control and treated eyes suggesting that toxicity is unlikely the reason for these phenotypic changes (Supplemental Figure 4B).

We were interested in the consequence of activating the Wnt pathway after lentigenic cell differentiation. We performed the same 24 hour $\mathrm{LiCl}$ exposure at stage 23 and find the lens smaller

172 and the anterior segment less thick than control animals, but lentigenic cells and lens tissue remain

173 identifiable. This suggests that ectopic Wnt signaling does not impact cell identity in differentiated 174 lentigenic cells (Figure 3M \& M').

175 The lack of lens growth in stage 21 treated animals may be a result of an imposed delay in 176 lens formation or it may be a result of the loss of lens potential. To differentiate between these 177 possibilities we allowed treated animals to recover. We bathed experimental and control embryos, 178 at both stage 21 and 23, for 24 hours, washed out the solution and allowed animals to develop for 179 an additional 48 hours. $\mathrm{LiCl}$ treated stage 21 embryos never recover a lens (Figure $4 \mathrm{~N}^{\&} 4 \mathrm{~N}^{\prime}$ ) 180 while $\mathrm{LiCl}$ treated stage 23 embryos do form a small but morphologically abnormal lens (Figure $\left.1814 \mathrm{O} \& 4 \mathrm{O}^{\prime}\right)$. This abnormal lens is larger than the lens found in animals immediately fixed after 182 treatment, suggesting that existing lentigenic cells at stage 23 continue to contribute to lens 183 formation and growth. However, because the stage 23 treated lens is markedly smaller than control, 184 it suggests that further lentigenic cell differentiation is lost in treated animals. These data suggest 185 that ectopic Wnt signaling leads to the disruption of lens potential and the lack of proper lentigenic 186 cell differentiation.

187 Despite the remarkable loss of the lens, these data do not clearly distinguish between the 188 loss of lentigenic cell fate or proper cell function, such as the growth of the cellular processes that 189 form the lens. To assess if lentigenic cell fate is lost, we performed in situ hybridization 190 experiments for DpS-Crystallin on $\mathrm{LiCl}$ treated animals. We saw two types of expression 191 phenotypes, either a significant decrease (Type I) or a complete loss (Type II) in DpS-Crystallin 192 expression as compared to control (Figure 4P, P' \& P')' We find all DpS-Crystallin expression 193 exclusively dorsal to the site of lens formation suggesting that these cells may differentiate first. 194 These data show that ectopic Wnt signaling results in the loss of lentigenic cell fate and that our 
treatment may have interrupted a dorsal-to-ventral wave of differentiation in some embryos (Figure 4A). In addition, we assessed other anterior segment markers, including DpSix3/6 and $D p L h \times 1 / 5$, and these genes show a consistent loss of expression in the most severe phenotypes, (Supplemental Figure 4C).

\section{Limb Patterning Program Regulatory Evolution}

To address if Wnt signaling is upstream of the limb patterning program, we performed in situ hybridization of limb transcription factors after LiCl treatment (Figure 3Q-3S, Supplementary Figure 4C). Similar to DpS-Crystallin expression, we again see a mild reduction (Type I) or loss and severe reduction (Type II) of expression. Our milder phenotypes, again, show a dorsal asymmetry, which can be most easily seen in DpSP6-9A, DpDlx and DpHbn (Figure 3Q, Q', Q', 3R, R', R' and 3S, S', S' '). Changes are also visible but less obvious in DpPbx and DpMeis expression, with $\mathrm{DpPbx}$ only showing a mild phenotype (Supplemental figure 4C). These data support the placement of Wnt signaling upstream of the limb patterning program in a negative regulatory role.

\section{Conclusion}

Our findings indicate that the limb patterning program has been co-opted for anterior segment and lens development in cephalopods and that this co-option does not have a homologous upstream regulatory relationship with Wnt signaling as found in the limb (Estella et al., 2003; Tarazona et al., 2019). This change in signaling and the known duplication of SP6-9 identifies the paralog SP6-9a as a mediator of limb patterning program co-option in the anterior segment. Finally, with little similarity between limb and lens, our work suggests that the function of the limb patterning program in a limbless ancestor was likely a more generic developmental function than outgrowth. Considering present findings, previous work and hypotheses we conclude that the ability to pattern in a radial fashion, as previously proposed, is a more inclusive and likely ancestral function (Figure 4B) (Carroll et al., 1994; Erwin \& Davidson, 2002). This work shows the cephalopod lens to be a unique context for future investigation of comparative regulatory changes responsible for co-option, and for identifying the regulatory mechanisms responsible for the emergent radial pattern found in embryos across species. 


\section{Methods}

\section{Animal Husbandry}

230 Doryteuthis pealeii egg sacks were obtained from the Marine Biological Labs. Egg sacks were

231 kept at 20 degrees Celsius. Although not required, European guidelines for cephalopod research

232 were followed.

\section{Histology and TUNEL Staining}

235 Embryos were fixed at 4 degrees Celsius overnight in 4\% PFA in filter-sterilized seawater. After 236 fixation embryos were transitioned into $15 \%$ and $30 \%$ sucrose and embedded in TFM and stored at -80 degrees Celsius. Embryos were cryosectioned in 12 um sections, stained with Sytox Green 1:1000 and Phalloidin 555 1:300 in PBS overnight (Molecular Probes). Tunel stained tissue was processed after sectioning using the Click-iT TUNEL Alexa Fluor 488 kit according to manufacturer's instructions (Invitrogen). Embryos were mounted in VECTASHIELD Hardset antifade mounting medium and imaged on a Zeiss 880 confocal.

\section{Homolog Identification and Phylogenetics}

244 Genes were preliminarily identified using reciprocal BLAST with Mus musculus and Drosophila 245 melanogaster sequences as bait with the exception of S-Crystallin where previous Doryteuthis 246 opalescens sequences were also used (Altschul et al., 1990). Top hits in the D. pealeii 247 transcriptome were trimmed for coding sequence and translated to amino acid sequences. To find 248 related sequences, BLASTp was used, searching only the RefSeq protein database in NCBI filtered

249 for vertebrate and arthropod models, as well as spiralian models for when published annotated 250 sequences could be found. The top hits of each gene name were downloaded and aligned with our 251 D. pealeii sequences for each tree using MAFFT in Geneious (Katoh, 2002). To check sequence 252 redundancy and proper outgroups quick trees were made using FastTree. We constructed 253 maximum-likelihood trees on the FASRC Cannon cluster supported by the FAS Division of 254 Science Research Computing Group at Harvard University (Price et al. 2010). Using PTHREADS 255 RAxML v.8.2.10, we ran the option for rapid bootstrapping with search for best maximum 256 likelihood tree, resampling with 1000 bootstrap replicates, the PROTGAMMAAUTO model of 257 amino acid substitution, and otherwise default parameters (Stamatakis, 2014). Fasta alignments, 258 Nexus tree files are found in the Supplemental Data Folder. All PDF versions of the trees are found 259 in Supplemental Figure 1. 


\section{Cloning and Probe Synthesis}

262 Embryos stg 21-29 were crushed in Trizol reagent. RNA was extracted using standard phenol263 chloroform extraction with a clean-up using the Qiagen RNeasy Micro kit. cDNA was synthesized 264 using iScript (Bio-Rad) according to manufacturer protocols. Primers were designed using Primer3 265 in the Geneious software package from available transcriptomic data (Koenig et al., 2016). PCR 266 products were ligated into the Pgem-T Easy plasmid and isolated using the Qiagen miniprep kit. 267 Plasmids were linearized using restriction enzymes. Sense and anti-sense probes were synthesized 268 using T7 and SP6 polymerase with digoxygenin labelled nucleotides.

\section{In situ Hybridization}

271 Embryos were fixed as previously described (Koenig et al. 2016) and were dehydrated in 100\% 272 ethanol and stored at -20 degrees Celsius. Whole-mount in situ hybridization was performed as 273 previously described (Koenig et al., 2016). Embryos were imaged using a Zeiss Axio Zoom.V16.

274 Embryos were fixed for sectioning overnight in 4\% PFA in artificial seawater and dehydrated in $275100 \%$ ethanol. Embryos were transitioned into histoclear and embedded in paraffin. Embryos were sectioned on a Leica RM2235 microtome in 5-micron sections. Sections were dewaxed for in situ

277 in Histoclear, rehydrated through an EtOH series, and re-fixed for 5 minutes at 4 degrees Celsius 278 in 4\% PFA in PBS. Embryos were exposed to Proteinase $\mathrm{K}$ for 20 minutes at 37 degrees Celsius 279 and then quenched with glycine. The embryos were then de-acetylated with acetic anhydride.

280 Slides were then pre-hybridized at 65 degrees Celsius for 30-60 minutes and then exposed to probe 281 overnight. Slides were washed in 50\% formamide/1x SSC/0.1\% Tween-20 hybridization buffer 282 twice, then twice in 1x SSC, .2x SSC and 0.02x SSC, all at 70 degrees Celsius. The slides were 283 then washed at room temperature in MABT three times and blocked in Roche Blocking Buffer for 284 an hour. Slides were incubated in Anti-Dig antibody (Roche) at 1/4000 overnight at 4 degrees 285 Celsius. Slides were washed with MABT and then placed in AP reaction buffer. Slides were then 286 exposed to BCIP/NBT solution until reacted and stopped in PBS. Slides were counterstained with 287 Sytox 1:1000 overnight. Slides mounted in ImmunoHistoMount (Abcam) and imaged on a Zeiss 288 Axioscope. DpS-Crystallin embryo in situs were transitioned to sucrose and embedded after 289 imaging in whole-mount. Embryos were image on a Zeiss Axioscope.

\section{Ex ovo Experimental Culture}

292 Ex ovo culture was performed as previously described in Koenig, 2016. Embryos were bathed in $293.25 \mathrm{M}, .15 \mathrm{M}$ and $.07 \mathrm{M} \mathrm{LiCl}$ and 100nm, 250nm and 500nm concentration of Wnt Agonist 
294 (CHIR99021) in Pen-Step filter-sterilized seawater to determine a working concentration. Control

295 animals were bathed in equivalent amounts of DMSO or Pen-Strep alone.

297 Supplemental Data Files

298 RAxML Maximum Likelihood trees, 1000 bootstraps.

299 ANTP_ML_1000bs_final.nex

300 Axin_ML_1000bs_final.nex

301 Cry_- ML_1000bs_final.nex

302 Dach_ML_1000bs_final.nex

303 Dsh $\bar{M} L \_\overline{1}$ 1000bs_final.nex

304 Fz_ML_1000bs_final.nex

305 GSK3_ML_1000bs_final.nex

306 Lhx_ML_1000bs_final.nex

307 LRP1_ML_1000bs_final.nex

308 Pangolin_ML_1000 bs_final.nex

309 Prd_domain_ $\bar{M} L$ 1000 bs_final.nex

310 TALE ML 1000bs final.nex

311 Wnt_M $\mathrm{M}$ _1000bs_final.nex

313 MAFFT sequence alignments

314 ANTP ML 1000bs final.fasta

315 Axin_M $\mathrm{ML}$ 1000bs_final.fasta

316 Cry_ML_1000bs_final.fasta

317 Dach_ML_1000bs_final.fasta

318 Dsh $\bar{M} L$ 1000bs final.fasta

319 Fz_ML_1000bs_final.fasta

320 GSK3_M ML_1000 bs_final.fasta

321 Lhx_ML_1000bs_final.fasta

322 LRP1_M $\bar{L} \_1000 \overline{b s}$ final.fasta

323 Pangolin_M $\bar{M} \_1000 \bar{b}$ s_final.fasta

324 Prd_domain_ML_1000̄bs_final.fasta

325 TALE_ML_1000bs_final.fasta

326 Wnt_ML_1000bs_final.fasta

\section{Authors' contributions}

329 K.M.K. designed the experiments. S.N., K.J.M., F.N., C.D., J.C., and K.M.K. performed

330 experiments. K.J.M. performed phylogenetic analyses. K.M.K., S.N., and K.J.M. wrote the 331 manuscript with consultation from all authors.

\section{Competing Interests}

334 Authors declare no competing interests. 


\section{Funding}

337 This work is supported by the Office of the NIH Director 1DP5OD023111-01, and the John 338 Harvard Distinguished Science Fellowship to K.M.K.

\section{Acknowledgements}

341 The authors would like to thank the Koenig and Srivastava lab members for helpful discussions as 342 well as Kevin Woods and the John Harvard Distinguished Science Fellows community for support.

343 We would like to thank Jeffrey Gross, Alex Schier, Mansi Srivastava, and Andrew Murray for 344 comments on the manuscript. We also thank the Marine Biological Labs, the Marine Resources 345 Center, Owen Nichols, Ernie Eldredge, and Shannon Eldredge for assisting in the acquisition of 346 embryos. We would also like to acknowledge the Harvard College undergraduates of LS50: 347 Integrated Science Laboratory Course: Zach Alerte, Vlad Batagui, Eli Burnes, Stephen Casper, 348 Chris Chen, Ahab Chopra, Ralph Estanboulieh, Lily Gao, Pedro Garcia, Saimun Habib, Harry 349 Hager, Maxwell Ho, Charlie Horowitz, Ray Jiang, Prashanth Kumar, Truelian Lee, Arian Mansur, 350 Matthew Mardo, Mark Theodore Meneses, Kendrick Nguyen, Francesco Rolando, Simon 351 Schnabl, Taylor Shirtliff-Hinds, Sorscher Lincoln, William Stainier, Avi Swartz, David Szanto, 352 Sophia Tang, Joey Toker, Analli Torres, Nina Uzoigwe, Rowen VonPlagenhoef, Evelyn Wong, 353 Alexandra Zaloga, Maxwell Zhu.

\section{References}

Altschul, S. F., Gish, W., Miller, W., Myers, E. W., \& Lipman, D. J. (1990). Basic local alignment search tool. Journal of molecular biology, 215(3), 403-410. doi: 10.1016/s00222836(05)80360-2

Angelini, D. R., \& Kaufman, T. C. (2005). Insect appendages and comparative ontogenetics. Developmental biology, 286(1), 57-77. doi: 10.1016/j.ydbio.2005.07.006

Arnold, J. M. (1965). Normal embryonic stages of the squid, Loligo pealii (Lesueur). The Biological Bulletin, 128(1), 24-32. doi: 10.2307/1539386

Arnold, J. M. (1966). On the occurrence of microtubules in the developing lens of the squid Loligo pealii. Journal of ultrastructure research, 14(5-6), 534-539. doi: 10.1016/s0022-5320(66)800801

Arnold, J. M. (1967). Fine structure of the development of the cephalopod lens. Journal of ultrastructure research, 17(5-6), 527-543. doi: 10.1016/s0022-5320(67)80139-4

Arendt, D., Hausen, H., \& Purschke, G. (2009). The 'division of labour'model of eye evolution. Philosophical Transactions of the Royal Society B: Biological Sciences, 364(1531), 2809-2817. doi: $10.1098 /$ rstb.2009.0104 
Brahma, S. K. (1978). Ontogeny of lens crystallins in marine cephalopods. Development, 46(1), 111-118. doi: 10.1016/b978-0-12-483180-3.50009-5

Beldade, P., Brakefield, P. M., \& Long, A. D. (2002). Contribution of Distal-less to quantitative variation in butterfly eyespots. Nature, 415(6869), 315. doi: 10.1038/415315a

Brakefield, P. M., Gates, J., Keys, D., Kesbeke, F., Wijngaarden, P. J., Monteiro, A., French, V., \& Carroll, S. B. (1996). Development, plasticity and evolution of butterfly eyespot patterns. Nature, 384(6606), 236. doi: 10.1038/384236a0

Campbell, G., \& Tomlinson, A. (1998). The roles of the homeobox genes aristaless and Distalless in patterning the legs and wings of Drosophila. Development, 125(22), 4483-4493.

Capellini, T. D., Zappavigna, V., \& Selleri, L. (2011). Pbx homeodomain proteins: TALEnted regulators of limb patterning and outgrowth. Developmental Dynamics, 240(5), 1063-1086. doi: $10.1002 / \mathrm{dvdy} .22605$

Carroll, S. B., Gates, J., Keys, D. N., Paddock, S. W., Panganiban, G. E., Selegue, J. E., \& Williams, J. A. (1994). Pattern formation and eyespot determination in butterfly wings. Science, 265(5168), 109-114. doi: 10.1126/science.7912449.

Carroll, S. B., Grenier, J. K., \& Weatherbee, S. D. (2013). From DNA to diversity: molecular genetics and the evolution of animal design. John Wiley \& Sons. doi: 10.1002/ajmg.a.20051

Chiou, S. H. (1984). Physicochemical characterization of a crystallin from the squid lens and its comparison with vertebrate lens crystallins. The Journal of Biochemistry, 95(1), 75-82. doi: 10.1093/oxfordjournals.jbchem.a134605

Chow, R. L., \& Lang, R. A. (2001). Early eye development in vertebrates. Annual review of cell and developmental biology, 17(1), 255-296. doi: 10.1146/annurev.cellbio.17.1.255

Cohen, S. M. (1990). Specification of limb development in the Drosophila embryo by positional cues from segmentation genes. Nature, 343(6254), 173. doi: doi: 10.1038/343173a0

Cvekl, A., \& Ashery-Padan, R. (2014). The cellular and molecular mechanisms of vertebrate lens development. Development, 141(23), 4432-4447. doi: 10.1242/dev.107953

Dakin, W. J. (1928). The eyes of Pecten, Spondylus, Amussium and allied Lamellibranchs, with a short discussion on their evolution. Proceedings of the Royal Society of London. Series B, Containing Papers of a Biological Character, 103(725), 355-365. doi:10.1098/rspb.1928.0047

Darwin, C. (2016). On the origin of species, 1859. Routledge.

Dong, P. S., Chu, J., \& Panganiban, G. (2001). Proximodistal domain specification and interactions in developing Drosophila appendages. Development, 128(12), 2365-2372.

Dong, P. S., Dicks, J. S., \& Panganiban, G. (2002). Distal-less and homothorax regulate multiple targets to pattern the Drosophila antenna. Development, 129(8), 1967-1974. 
Estella, C., Rieckhof, G., Calleja, M., \& Morata, G. (2003). The role of buttonhead and Sp1 in the development of the ventral imaginal discs of Drosophila. Development, 130(24), 5929-5941. doi: $10.1242 /$ dev.00832

Estella, C., Voutev, R., \& Mann, R. S. (2012). A dynamic network of morphogens and transcription factors patterns the fly leg. In Current topics in developmental biology (Vol. 98, pp. 173-198). Academic Press. doi: 10.1016/B978-0-12-386499-4.00007-0

Erwin, D. H., \& Davidson, E. H. (2002). The last common bilaterian ancestor. Development, 129(13), 3021-3032.

Grimmel, J., Dorresteijn, A. W., \& Fröbius, A. C. (2016). Formation of body appendages during caudal regeneration in Platynereis dumerilii: adaptation of conserved molecular toolsets. EvoDevo, 7(1), 1-14.

Hedgepeth, C. M., Conrad, L. J., Zhang, J., Huang, H. C., Lee, V. M., \& Klein, P. S. (1997). Activation of the Wnt signaling pathway: a molecular mechanism for lithium action. Developmental biology, 185(1), 82-91. doi: 10.1006/dbio.1997.8552

Ibarretxe, G., Aurrekoetxea, M., Crende, O., Badiola, I., Jimenez-Rojo, L., Nakamura, T., ... \& Unda, F. (2012). Epiprofin/Sp6 regulates Wnt-BMP signaling and the establishment of cellular junctions during the bell stage of tooth development. Cell and tissue research, 350(1), 95-107. doi: $10.1007 / \mathrm{s} 00441-012-1459-8$

Jonasova, K., \& Kozmik, Z. (2008, April). Eye evolution: lens and cornea as an upgrade of animal visual system. In Seminars in cell \& developmental biology (Vol. 19, No. 2, pp. 71-81). Academic Press. doi: 10.1016/j.semcdb.2007.10.005

Katoh, K., Misawa, K., Kuma, K. I., \& Miyata, T. (2002). MAFFT: a novel method for rapid multiple sequence alignment based on fast Fourier transform. Nucleic acids research, 30(14), 3059-3066. doi: 10.1093/nar/gkf436

Klein, P. S., \& Melton, D. A. (1996). A molecular mechanism for the effect of lithium on development. Proceedings of the National Academy of Sciences, 93(16), 8455-8459. doi: 10.1073/pnas.93.16.8455

Koenig, K. M., Sun, P., Meyer, E., \& Gross, J. M. (2016). Eye development and photoreceptor differentiation in the cephalopod Doryteuthis pealeii. Development, 143(17), 3168-3181. doi: $10.1242 /$ dev.134254

Koenig, K. M., \& Gross, J. M. (2020) Evolution and development of complex eyes: A celebration of diversity. Development, 147(19). doi: 10.1242/dev.182923

Lapan, S. W., \& Reddien, P. W. (2011). dlx and sp6-9 Control optic cup regeneration in a prototypic eye. PLoS Genet, 7(8), e1002226. doi: 10.1371/journal.pgen.1002226

Lemons, D., Fritzenwanker, J. H., Gerhart, J., Lowe, C. J., \& McGinnis, W. (2010). Co-option of an anteroposterior head axis patterning system for proximodistal patterning of appendages in early bilaterian evolution. Developmental biology, 344(1), 358-362. 
477

Maas, R., \& Bei, M. (1997). The genetic control of early tooth development. Critical Reviews in Oral Biology \& Medicine, 8(1), 4-39. doi: 10.1177/10454411970080010101

Mazza, M. E., Pang, K., Reitzel, A. M., Martindale, M. Q., \& Finnerty, J. R. (2010). A conserved cluster of three PRD-class homeobox genes (homeobrain, rx and orthopedia) in the Cnidaria and Protostomia. EvoDevo, 1(1), 3.

McCulloch, K. J., \& Koenig, K. M. (2020). Krüppel-like factor/specificity protein evolution in the Spiralia and the implications for cephalopod visual system novelties. Proceedings of the Royal Society B, 287(1937), 20202055. doi: 10.1098/rspb.2020.2055

McDougall, C., Korchagina, N., Tobin, J. L., \& Ferrier, D. E. (2011). Annelid Distal-less/Dlx duplications reveal varied post-duplication fates. BMC evolutionary biology, 11(1), 1-16.

Meinertzhagen, I. A. (1990). Development of the squid's visual system. In Squid as experimental animals (pp. 399-419). Springer, Boston, MA.

Mercader, N., Leonardo, E., Azpiazu, N., Serrano, A., Morata, G., Martínez-A, C., \& Torres, M. (1999). Conserved regulation of proximodistal limb axis development by Meis1/Hth. Nature, 402(6760), 425-429. doi: 10.1038/46580

Minelli, A. (2000). Limbs and tail as evolutionarily diverging duplicates of the main body axis. Evolution \& development, 2(3), 157-165. doi: 10.1046/j.1525-142x.2000.00054.x

Moczek, A. P., \& Rose, D. J. (2009). Differential recruitment of limb patterning genes during development and diversification of beetle horns. Proceedings of the National Academy of Sciences, 106(22), 8992-8997.

Nilsson, D. E. (2013). Eye evolution and its functional basis. Visual neuroscience, 30(1-2), 5-20. doi: $10.1017 / \mathrm{S} 0952523813000035$

Ogura, A., Yoshida, Ma., Moritaki, T., Plida,Y., Sese, J., Shimizu, K., Sousounis, K., \& Tsonis, P. A. (2013) Loss of the six3/6 controlling pathways might have resulted in pinhole-eye evolution in Nautilus. Scientific Reports 3, 1432. doi: 10.1038/srep01432

Packard, A. (1972). Cephalopods and fish: the limits of convergence. Biological Reviews, 47(2), 241-307.

Panganiban G., Irvine S.M., Lowe C., Roehl H., Corley L.S., Sherbon B., Grenier J.K., Fallon J.F., Kimble J., Walker M., Wray G.A., Swalla B.J., Martindale M.Q., \& Carroll S.B. (1997). The origin and evolution of animal appendages. Proceedings of the National Academy of Sciences. 94(10):5162-6. doi: 10.1073/pnas.94.10.5162.

Panganiban, G., Nagy, L., \& Carroll, S. B. (1994). The role of the Distal-less gene in the development and evolution of insect limbs. Current Biology, 4(8), 671-675. doi: 10.1016/s09609822(00)00151-2

Panganiban, G., \& Rubenstein, J. L. (2002). Developmental functions of the Distal-less/Dlx homeobox genes. Development, 129(19), 4371-4386. 
Pueyo, J. I., \& Couso, J. P. (2005). Parallels between the proximal-distal development of vertebrate and arthropod appendages: homology without an ancestor?. Current opinion in genetics \& development, 15(4), 439-446. doi: 10.1016/j.gde.2005.06.007

Plavicki, J. S., Squirrell, J. M., Eliceiri, K. W., \& Boekhoff-Falk, G. (2016). Expression of the Drosophila homeobox gene, Distal-less, supports an ancestral role in neural development. Developmental Dynamics, 245(1), 87-95. doi: 10.1002/dvdy.24359

Price, M. N., Dehal, P. S., \& Arkin, A. P. (2010). FastTree 2-approximately maximumlikelihood trees for large alignments. PloS one, 5(3), e9490. doi: 10.1371/journal.pone.0009490

Prpic, N. M., \& Tautz, D. (2003). The expression of the proximodistal axis patterning genes Distal-less and dachshund in the appendages of Glomeris marginata (Myriapoda: Diplopoda) suggests a special role of these genes in patterning the head appendages. Developmental biology, 260(1), 97-112. doi: 10.1016/s0012-1606(03)00217-3

Prpic, N. M. (2019). Limb Development: A lesson in homology. eLife, 8, e48335. doi: $10.7554 /$ eLife. 48335

Ramanathan, A., Srijaya, T. C., Sukumaran, P., Zain, R. B., \& Kasim, N. H. A. (2018). Homeobox genes and tooth development: Understanding the biological pathways and applications in regenerative dental science. Archives of oral biology, 85, 23-39. doi: 10.1016/j.archoralbio.2017.09.033

Sanz-Navarro, M., Delgado, I., Torres, M., Mustonen, T., Michon, F., \& Rice, D. P. (2019). Dental Epithelial Stem Cells Express the Developmental Regulator Meis1. Frontiers in physiology, 10, 249. doi: 10.3389/fphys.2019.00249

Sato, N., Meijer, L., Skaltsounis, L., Greengard, P., \& Brivanlou, A. H. (2004). Maintenance of pluripotency in human and mouse embryonic stem cells through activation of Wnt signaling by a pharmacological GSK-3-specific inhibitor. Nature medicine, 10(1), 55-63. doi: 10.1038/nm979

Schiemann, S. M., Martín-Durán, J. M., Børve, A., Vellutini, B. C., Passamaneck, Y. J., \& Hejnol, A. (2017). Clustered brachiopod Hox genes are not expressed collinearly and are associated with lophotrochozoan novelties. Proceedings of the National Academy of Sciences, 114(10), E1913-E1922. doi: 10.1073/pnas.1614501114

Setton, E. V., \& Sharma, P. P. (2018). Cooption of an appendage-patterning gene cassette in the head segmentation of arachnids. Proceedings of the National Academy of Sciences, 115(15), E3491-E3500. doi: 10.1073/pnas.1720193115

Shubin, N., Tabin, C., \& Carroll, S. (1997). Fossils, genes and the evolution of animal limbs. Nature, 388(6643), 639-648. doi: 10.1038/41710

Shubin, N., Tabin, C., \& Carroll, S. (2009). Deep homology and the origins of evolutionary novelty. Nature, 457(7231), 818-823. doi: 10.1038/nature07891

Stamatakis, A. (2014). RAxML version 8: a tool for phylogenetic analysis and post-analysis of large phylogenies. Bioinformatics, 30(9), 1312-1313. doi: 10.1093/bioinformatics/btu033 
577 Tarazona, O. A., Lopez, D. H., Slota, L. A., \& Cohn, M. J. (2019). Evolution of limb

578 development in cephalopod mollusks. eLife, 8, e43828. doi: 10.7554/eLife.43828

579 Walls, G. L. (1939). Origin of the vertebrate eye. Archives of Ophthalmology, 22(3), 452-486.

581 West, J. A., Sivak, J. G., \& Doughty, M. J. (1995). Microscopical evaluation of the crystalline 582 lens of the squid (Loligo opalescens) during embryonic development. Experimental eye 583 research, 60(1), 19-35. doi: 10.1016/s0014-4835(05)80080-6

585 West, J. A., Sivak, J. G., Pasternak, J., \& Piatigorsky, J. (1994). Immunolocalization of S-

586 crystallins in the developing squid (Loligo opalescens) lens. Developmental dynamics, 199(2),

587 85-92. doi: 10.1002/aja.1001990202

589 Williams, L. W. (1909). Anatomy of the Common Squid, Loligo pealii, Lesueur. London: E.J.

590 Brill. 

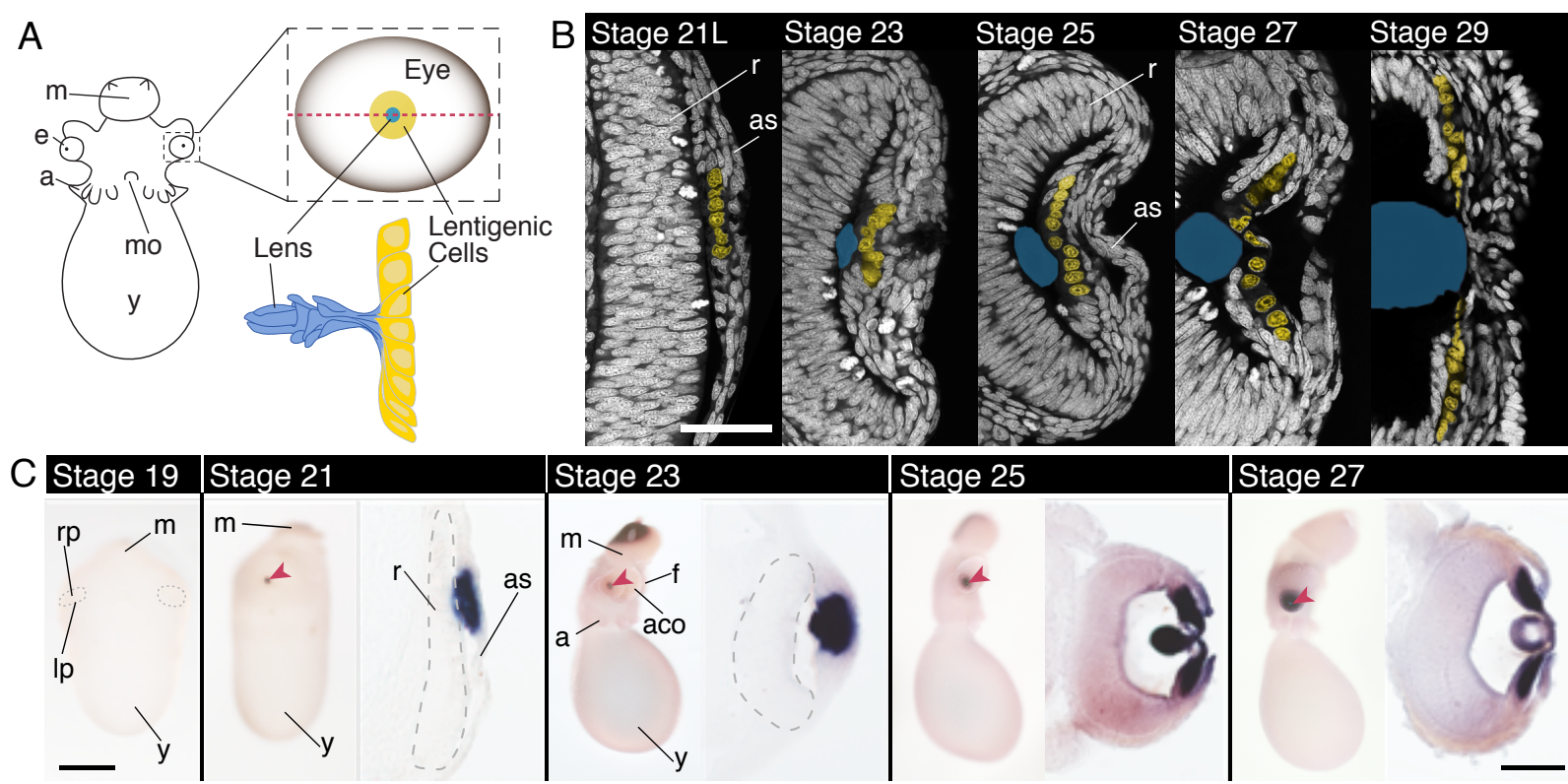

Stage 27

Figure 1: Lentigenic cell differentiation and DpS-Crystallin expression in the squid

A) Cartoon diagram of a squid embryo (anterior), en face cartoon of the developing eye (red dotted line shows cross-section plane) and developing lentigenic cells and lens. (Cartoon of lens and lentigenic cells based on Arnold, 1967) B) Cross-section of the developing anterior segment at Arnold stages 21 late, 23, 25, 27 and 29 identifying differentiation of lentigenic cells (Arnold, 1968). White: Sytox-Green labeling nuclei, Yellow: False-colored lentigenic cell nuclei corresponding to the LC2 population identified by nuclear morphology (Arnold, 1967; West et al., 1995; Koenig et al., 2016). Blue is the outline of the lens, as identified using phalloidin staining

601 (not shown). First evidence of LC2 cells is late stage 21. Lentigenic cell number multiplies and distribution grows across the anterior segment (as) throughout development. Scale is 50 microns. C) In situ hybridization of DpS-Crystallin in whole-mount and cryo-section. Stage 19 is an anterior view, the boundary between the retina placode and the lip cells is highlighted with a dotted line. No DpS-Crystallin expression is apparent at this stage. Stage 21-27 are shown in a lateral view of the embryo on the left and a cross-section of the eye on the right. Anterior of the embyro is down in the sections. The retina is outlined with a dashed grey line in stage 21 and 23. DpS-Crystallin expression corresponds with LC2 lentigenic cell population. Scale is 500 microns in whole mount images. Scale is 100 microns in sectioned images. as, anterior segment; $a$, arm; aco, anterior chamber organ; $e$, eye; $f$, funnel $l p$, lip; $m$, mantle; $m o$, mouth; $r p$, retina placode; $r$, retina; $y$, yolk. 


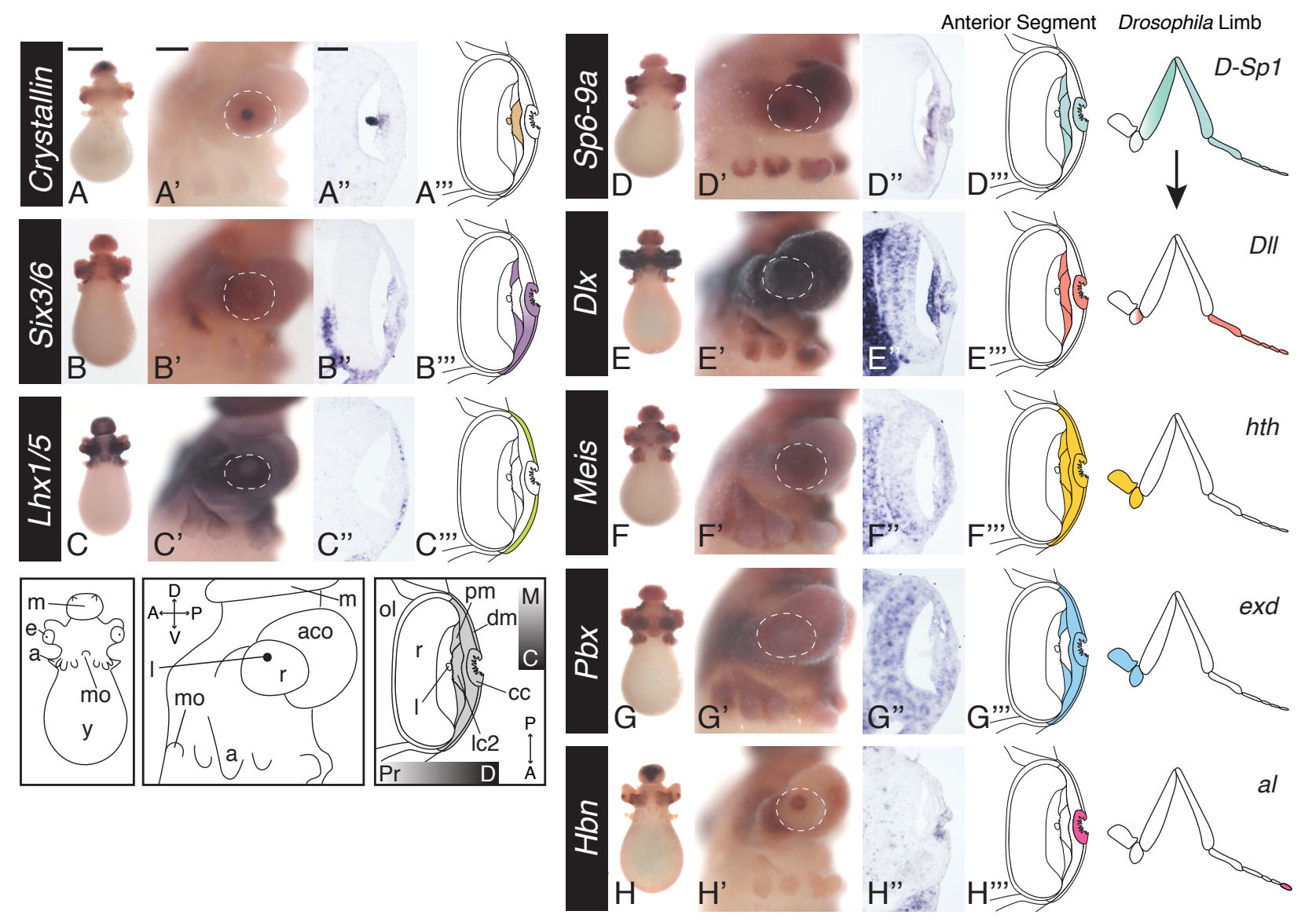
cross-section (anterior is down), cartoon summary of anterior segment expression. Dotted white outline in lateral view outlines the perimeter of the eye. A-C) Defining cell populations in the developing anterior segment at stage 23. A, A', A") DpS-Crystallin expression in the anterior segment at stage 23 , expressed in the proximal, central cells corresponding with the LC2 cells $(l c 2)$. Expression is also apparent in the lens. B, B', B'") Expression of DpSix3/6. B'") Expression is apparent in the distal, central cup cells $(c c)$ and the proximal-marginal $(p m)$ anterior segment cells. The proximal-central cells (lc2) lack expression of DpSix3/6. C, C', C') DpLhxl/5 expression. C") Expression of $D p L h x 1 / 5$ is found in the distal-marginal cell $(\mathrm{dm})$ population. Expression is excluded from the central cup (cc). D-G) Expression of the limb patterning program genes. Summary of the proximodistal expression of each Drosophila homolog during proximodistal patterning of the limb is shown on the right $\mathrm{H}$ ) Prd-like homolog Homeobrain $(\mathrm{Hbn})$ expression in the distal, central cup cells. $a$, arms; $a c o$, anterior chamber organ; $c c$, cup cells; $d m$, distal-marginal cells; $e$, eye; $l$, lens; $l c 2$, LC2 cells; $m$, mantle; $m o$, mouth; $p m$, proximal-marginal cells; $\mathrm{r}$, retina; $y$, yolk. Anterior segment highlighted in grey in the cartoon. Orientation abbreviations: M, marginal; C, central; Pr, proximal; D, Distal; A, anterior; P, posterior. Scale for whole-mount anterior view is 500 microns. Scale for lateral whole-mount view 200 microns. Scale for sectioned images 50 microns. 

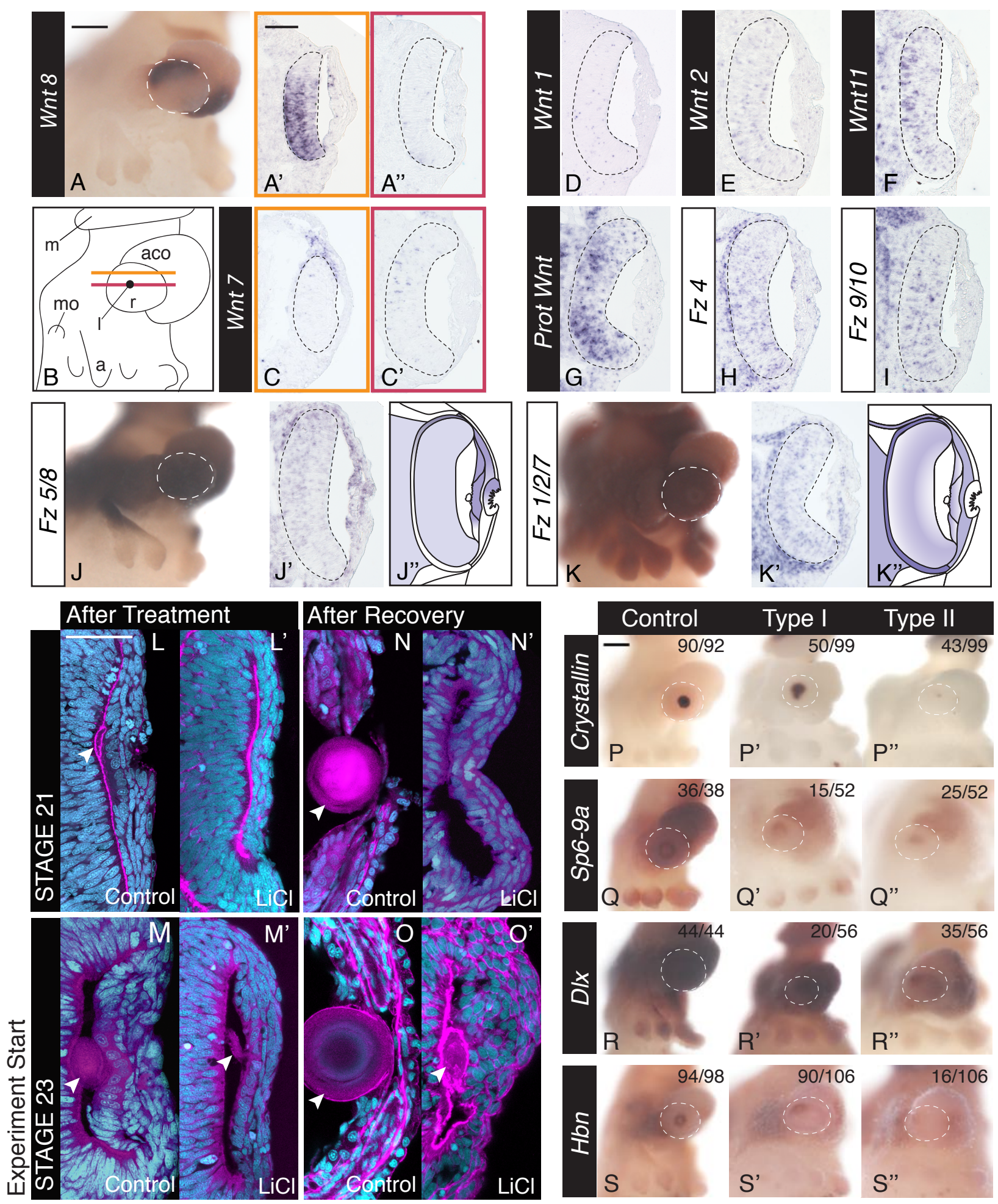

Figure 3: Wnt signaling pathway expression in the developing cephalopod eye

633 A-G) Wnt gene expression at stage 23. Based on expression, Wnt7, Wn8, Wnt2, Wnt11 and Prot

634 Wnt are possible candidates to signal the anterior segment. A) Lateral, whole-mount expression of

635 Wnt8. A') Dorsal retina expression of Wnt8. Location of the section indicated by the orange line

636 in B. A") Central section lacking retina expression. Location of the section indicated by the red

637 line in B. B) Cartoon of the lateral whole-mount embryo at stage 23. Orange and red lines 638 correspond to the location of the two sections shown in A, A', and C, C'. D-G) Expression of other Wnt homologs in central sections. H-K) Expression of Frizzled receptors at stage 23. Fz1/2/7 
640 shows asymmetric expression and Fz5/8 shows specific exclusion from the central cup cells. J 641 and $\mathrm{K}$ are lateral view of the whole mount expression. J' and $\mathrm{K}$ ', are cartoons of expression in J' 642 and $\mathrm{K}$ ' respectively. Black dotted line in sectioned images show the perimeter of the retina. L-O) 643 Anterior segment and lens morphology after Wnt agonist treatment ( $\mathrm{LiCl})$. Embryos were 644 cryosectioned and stained with sytox-green (nuclei, cyan) and phalloidin (F-actin, magenta).. L 645 and $\left.\mathrm{L}^{\prime}\right)$ Control and $\mathrm{LiCl}$ agonist treatments started at stage 21, treated for 24 hours and fixed 646 immediately. $\mathrm{M}$ and $\mathrm{M}^{\prime}$ ) Control and Wnt agonist ( $\left.\mathrm{LiCl}\right)$ treatments started at stage 23 for 24 hours 647 and fixed immediately. $\mathrm{N}$ and $\mathrm{N}^{\prime}$ ) Control and Wnt agonist ( $\left.\mathrm{LiCl}\right)$ treatments started at stage 21, 648 treated for 24 hours and allowed to recover for 48 hours and fixed. $\mathrm{O}$ and O') Control and Wnt 649 agonist $(\mathrm{LiCl})$ treatments started at stage 23, treated for 24 hours and allowed to recover for 48 650 hours and fixed. Arrowhead highlights the lens. P-S) In situ hybridization of anterior segment 651 markers after 24 hour control and $\mathrm{LiCl}$ treatments starting at stage 23. Phenotypes are characterized 652 as Type I (mild) and Type II (severe). The white dotted line outlines the eye in the lateral image 653 and the number of eyes scored in control and the two phenotypes is found in $\mathrm{LiCl}$ treated animals 654 in the top right corner. Scale for all lateral whole-mount view images is 200 microns. Scale for all 655 sectioned images is 50 microns. Anterior is down in all sectioned images. White dotted line in 656 whole mount images identify the perimeter of the eye. $m$, mantle; $a$, arms; aco, anterior chamber 657 organ; mo, mouth; $r$, retina; $l$, lens. 
bioRxiv preprint doi: https://doi.org/10.1101/2021.04.22.441006; this version posted April 23, 2021. The copyright holder for this preprint (which was not certified by peer review) is the author/funder, who has granted bioRxiv a license to display the preprint in perpetuity. It is made available under aCC-BY-NC-ND 4.0 International license.

A

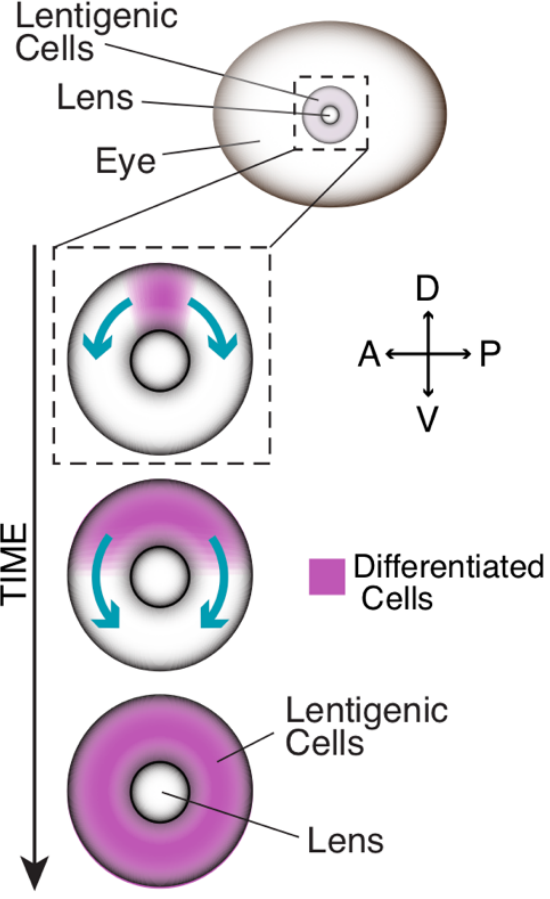

B

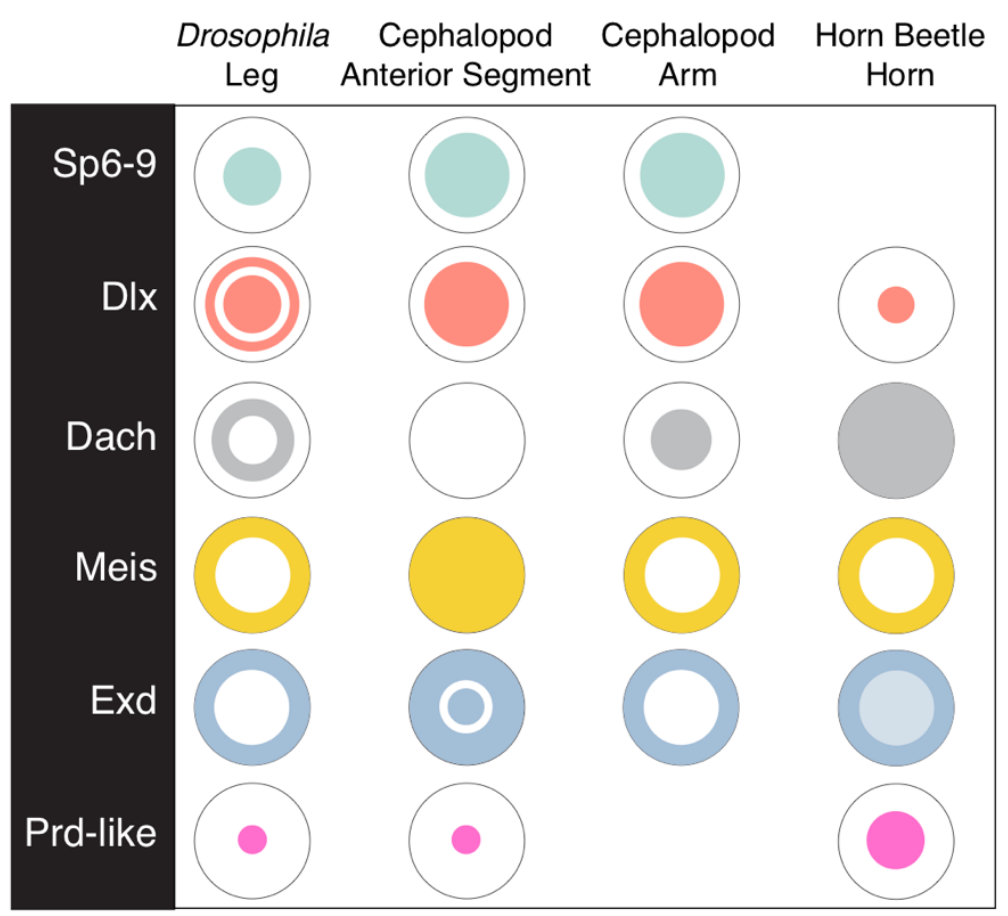

659

660

661

662

663

664

665

666

\section{Figure 4: Ectopic Wnt signaling activation leads to loss of the lens}

A) Model for lentigenic cell differentiation at stage 21. LC2 lentigenic cells differentiate on the dorsal side of the eye first, with a wave moving ventrally. Type I DpS-Crystallin embryos have been interrupted in progress. B) En face summary of sample radial expression of the limb patterning program across developmental contexts (Tarazona, 2019; reviewed in Moczek, 2009 and Angelini \& Kaufman, 2005). 


\section{Supplemental Tables}

668 Supplemental Table 1: All Primer sequences

\begin{tabular}{|l|l|l|}
\hline & Forward & Reverse \\
\hline DpS-Crystallin & GAACATCATGTCGCACCACG & AGTTGCTCGCCTGAGAAGAC \\
\hline DpLhx1/5 & GAAGTGTCTTCGTGCTCCCA & ATTATCGACCGGCGAGGAAC \\
\hline DpDlx & GGCAAGGCTTGGGTAAAACG & GGGGTAGCAGCGATGAGTTT \\
\hline DpMeis & TAGCGTTTCCAAAAGGACCT & CCCCAATACCCGTCATACTC \\
\hline DpPbx & TACTTCGGGAGCAGAGTCGA & TAGCGGTCGTCGTCGTAATG \\
\hline DpHbn & ATACAACGACGACGACCACC & CGCGTGAATACATCCGGGTA \\
\hline DpPrdl-1 & AGAACAACCCAACGTACACA & GCAAACATCGAGTGAATCCC \\
\hline DpPrdl-2 & TCGCATTGAGGATTGATCTT & GGTTGTTGTTGTTGTGTTGTT \\
\hline DpDac & CTGTATGGCTCCAAGTCCTC & GATCTCTGGTCGTCGTTTCA \\
\hline DpGSK3 & GATACGGGTGAACTGGTAGCAATC & CACCAACTGGATAGCCTCTGATG \\
\hline DpLRP1 & TTCCTTGAATAGCCTCATCGGTC & TTCCAAAAAGTGGGTGTGCG \\
\hline DpAxin & CCCTCATTATTCTCCAACCTCCTC & CACAGAGCACTTCAAAAACGGG \\
\hline DpTCF/LEF & GCTTGGGTGGCAAAATGTCG & TGCTGGACTGTTCTGGCAAAC \\
\hline DpDvl & GCAGGCACTTTTTTAGTAGCGTG & ATGTCCGTTGATGCGAGGTG \\
\hline DpWnt-Prot & GACAGCCTACCTTTATGCCA & TACATTCGCAGTCTTCCGTT \\
\hline DpWnt1 & GTTTGCTTGTATTCGTGCGA & CCCTCCAATCCCAATGAAGT \\
\hline DpWnt2 & GTCGTTTGTGGTCCTTGTTG & GAATGTCAGTTCCAGTTGCG \\
\hline DpWnt7 & GTGCGTTGATGAATCTCCAC & TGTACTCCTCCGTCTTGTTG \\
\hline DpWnt8 & CTGCCAGATACTCCGTGACATTTAC & TTGGTTGGGGATCGCACTG \\
\hline DpWnt11 & CTTGACATAGCAGCACCACACG & GAACAGTTTGCCAACAGAAGATGG \\
\hline DpFz9/10 & CGTAGTTTCTTGCCCGTAGAC & CGCTGTTTTGTATCAACCCCA \\
\hline DpFz1/2/7 & AAAGCCCCTTAAAGCATCCA & GACCATGCAATTCCACCTTG \\
\hline DpFz4 & TCAGTTCGTCAGCATCAACAT & CCGATATCCTCAACTGCACAA \\
\hline DpFz5/8 & TATTTGCTACCCACGGATCGC & CCGACCACCAAACACATAAAGT \\
\hline
\end{tabular}


bioRxiv preprint doi: https://doi.org/10.1101/2021.04.22.441006; this version posted April 23, 2021. The copyright holder for this preprint (which was not certified by peer review) is the author/funder, who has granted bioRxiv a license to display the preprint in perpetuity. It is made available under aCC-BY-NC-ND 4.0 International license.

\section{Supplemental Figure titles}

671 Sup Figure 1: Maximum-likelihood phylogenetic trees for genes identified in this study 
- XP_011414574.1_PREDICTED_homeobox_protein_EMX1_isoform_X1_Crassostrea_gigas_

ADG26729.1_EMX_homeobox_protein_partial_Platynereis_dumerilii_

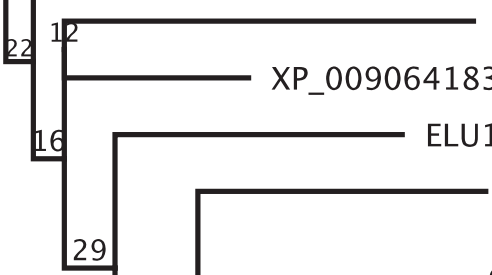

istps://doi.org 10.11d1/2021.04.22,441006:97 was not certified by peer reviev) is the author/funder, who hlas gnt inted bioRxiv a license to display the preprint in perpetuity. It is made

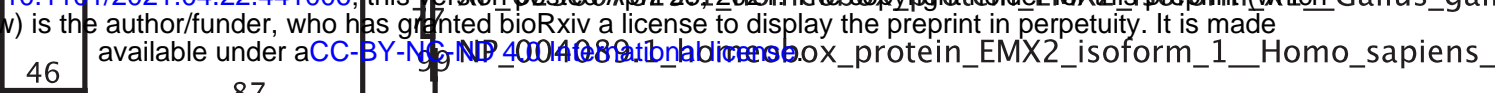

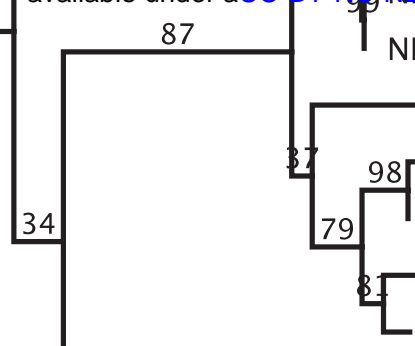

NP_034262.2_homeobox_protein_EMX2_Mus_musculus

NP_571354.1_empty_spiracles_homeobox_3_Danio_rerio_

[XP_011530999.1_homeobox_protein_EMX1_isoform_X2_Homo_sapiens_

44 NP_001107793.1_empty_spiracles_Tribolium_castaneum_

55_EFX74198.1_hypothetical_protein_DAPPUDRAFT_38036_partial_Daphnia_pulex_

NP_731868.1_empty_spiracles_Drosophila_melanogaster_

96

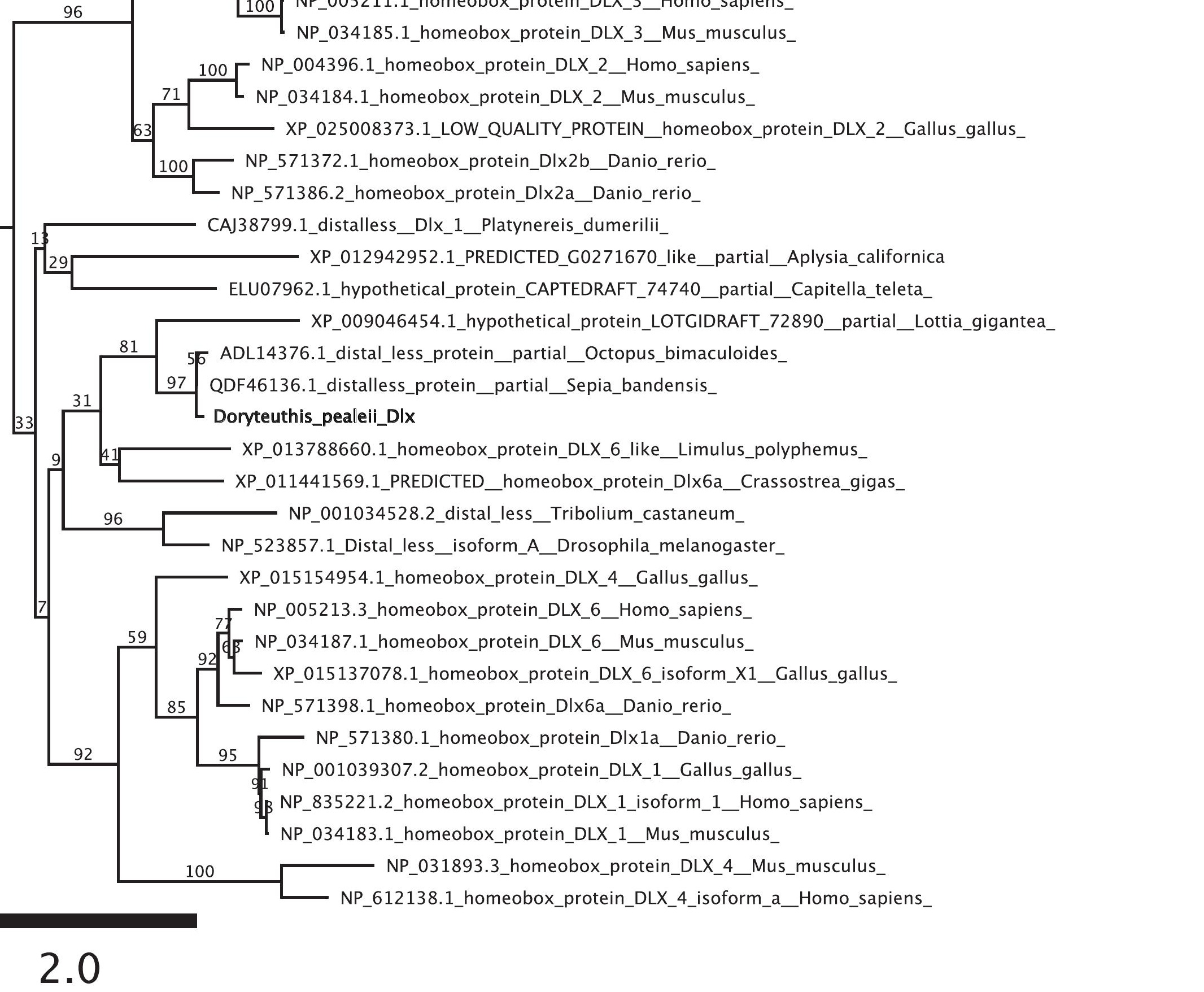




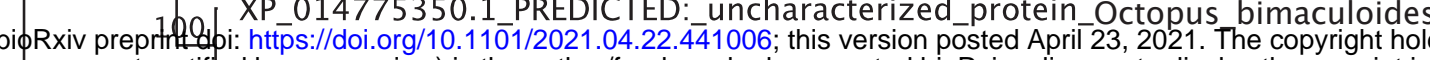

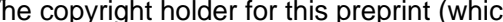

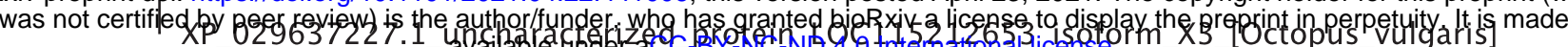
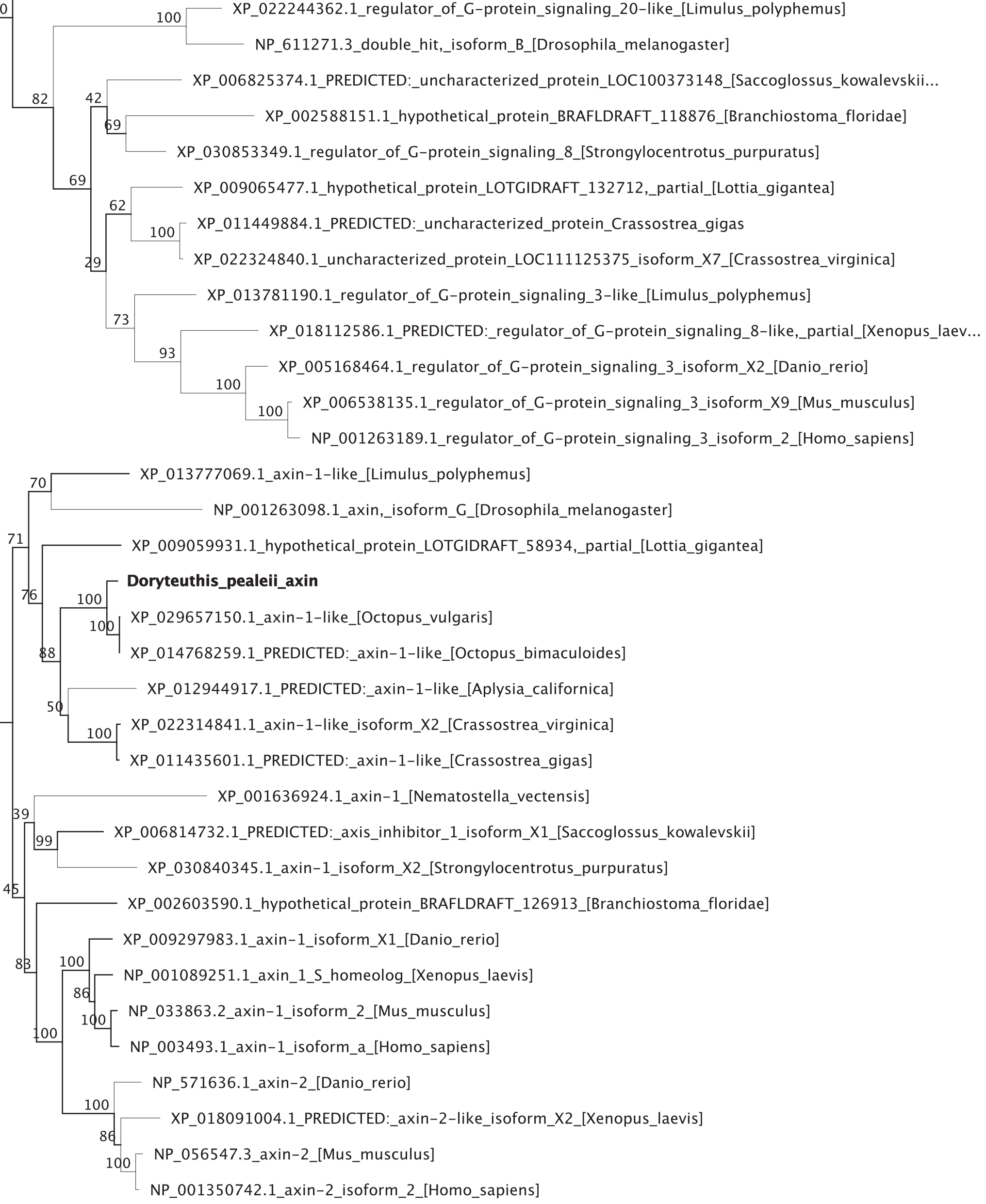





81

\section{9}

73

AHA91760.1_Dac_variant_2_partial_Euprymna_scolopes_

XP_021340456.1_dachshund_homolog_1_like_isoform_X1_Mizuhopecten_yessoensis_

85

64

XP_011445430.1_PREDICTED_dachshund_homolog_1_Crassostrea_gigas_

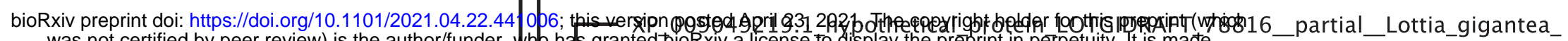
was not certified by peer review) is the author/funder, wh has granted bio Rxiv a license to display the preprint in perpetuity. It is made available under act $Y-N$ \&-ND 4.0 International license.

XP_005106037.2_PREDICTED_dachshund_homolog_1_like_partial_Aplysia_californica_

ELT93383.1_hypothetical_protein_CAPTEDRAFT_137512_Capitella_teleta_

81

71

ADG26728.1_dachshund_protein_partial_Platynereis_dumerilii_

88

NP_723968.1_dachshund_isoform_C_Drosophila_melanogaster_

XP_022238164.1_dachshund_homolog_1_like_isoform_X1_Limulus_polyphemus_

XP_019645878.1_PREDICTED_dachshund_homolog_1_like_isoform_X1_Branchiostoma_belcheri_

XP_011533243.1_dachshund_homolog_1_isoform_X4_Homo_sapiens_

100

88

[ NP_001033699.1_dachshund_homolog_1_isoform_2_Mus_musculus_

L8 XP_015130690.1_dachshund_homolog_1_isoform_X2_Gallus_gallus_

99 NP_001074142.1_dachshund_homolog_1_Danio_rerio_

NP_001038701.1_dachshund_c_Danio_rerio_

NP_001136042.1_dachshund_homolog_2_isoform_1_Mus_musculus_

$89 \square$

75

NP_001132986.1_dachshund_homolog_2_isoform_b_Homo_sapiens_

69 XP_025005272.1_dachshund_homolog_2_isoform_X2_Gallus_gallus_

95 NP_694487.2_dachshund_homolog_2_Danio_rerio_

XP_009304051.1_dachshund_b_isoform_X1_Danio_rerio_

N_vectensis_jgi_Dach_combined_protein_ID_107148_207853_translation

XP_015132896.1_SKI_family_transcriptional_corepressor_2_Gallus_gallus_

99

[NP_001103213.1_SKI_family_transcriptional_corepressor_2_Mus_musculus_ 100

95

[ NP_001264992.1_SKI_family_transcriptional_corepressor_2_isoform_1_Homo_sapiens_

\section{Doryteuthis_pealeiii_ski}




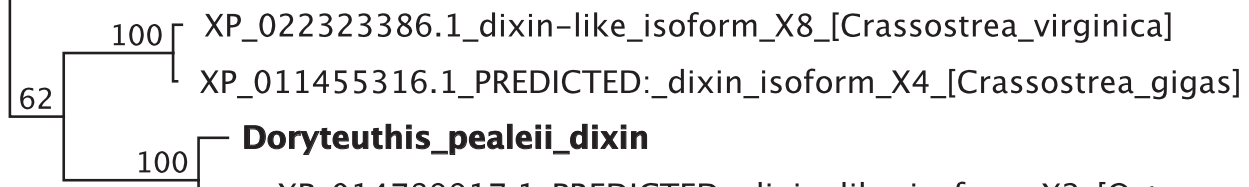

00 [ XP_014789917.1_PREDICTED:_dixin-like_isoform_X2_[Octopus_bimaculoides]

[XP_029647261.1_dixin-like_[Octopus_vulgaris]

[XP_005163733.1_discs_large_homolog_1-like_protein_isoform_X14_[Danio_rerio]

9才[ XP_018119119.1_PREDICTED:_disks_large_homolog_1_isoform_X13_[Xenopus_laevis]

100

98[ XP_011510811.1_disks_large_homolog_1_isoform_X14_[Homo_sapiens]

NP_001239363.1_disks_large_homolog_1_isoform_3_[Mus_musculus]

57

NP_001096956.1_discs_large_1,_isoform_L_[Drosophila_melanogaster]

95

29648064.1_disks_large_homolog_1-like_isoform_X5_[Octopus_vulgaris]

XP_014784184.1_PREDICTED:_disks_large_homolog_4-like_[Octopus_bimaculoides]

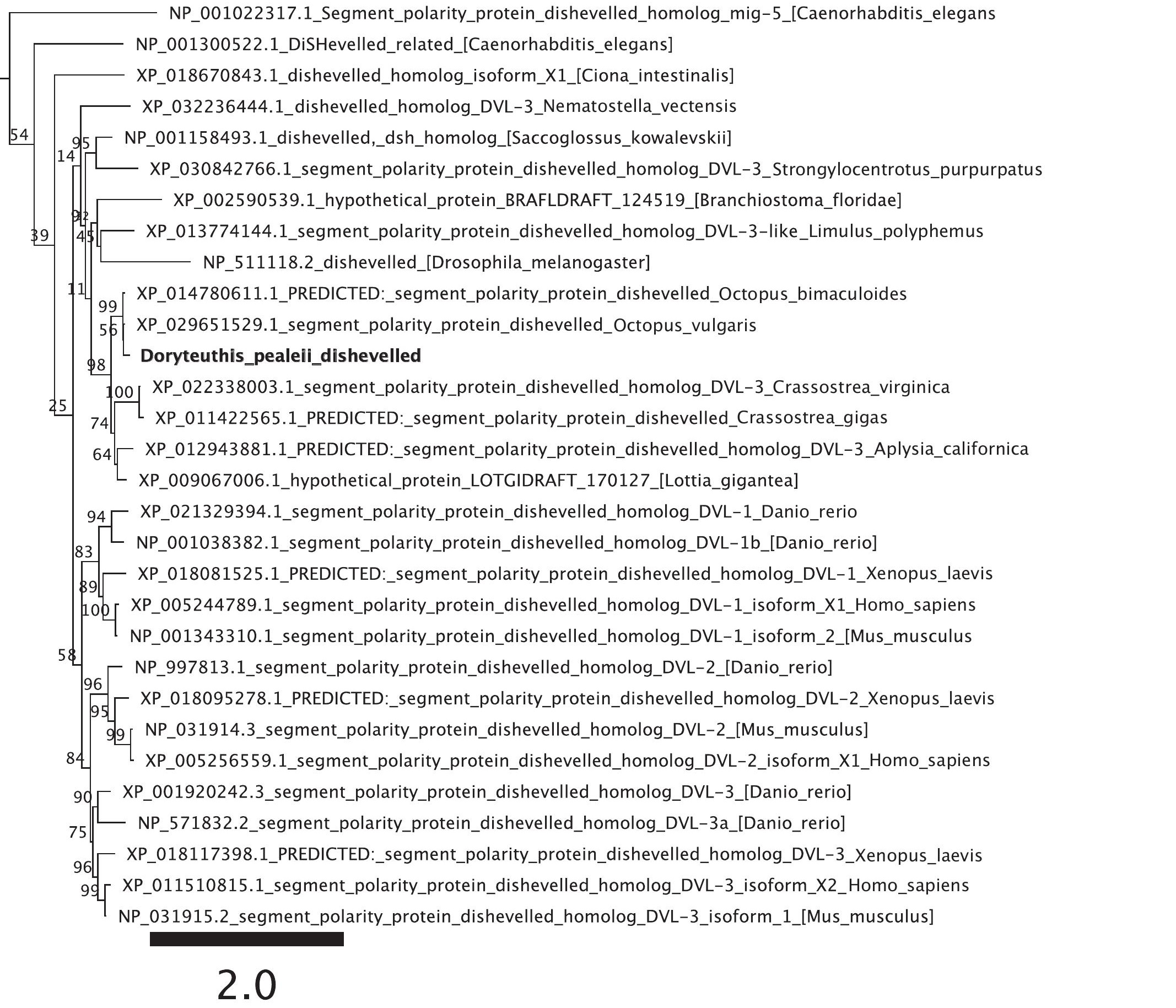




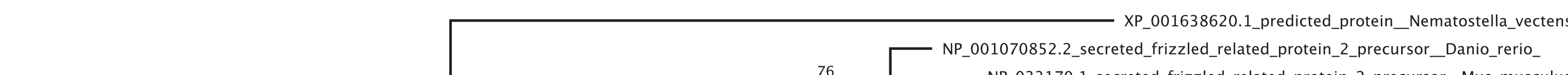

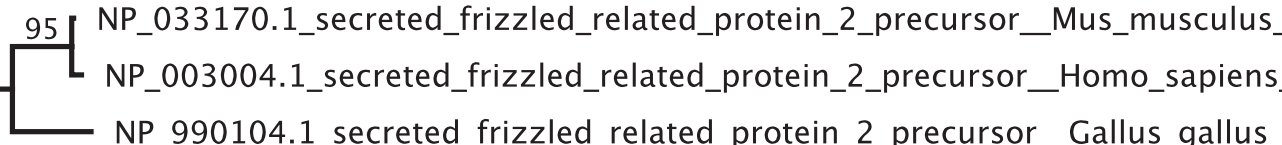

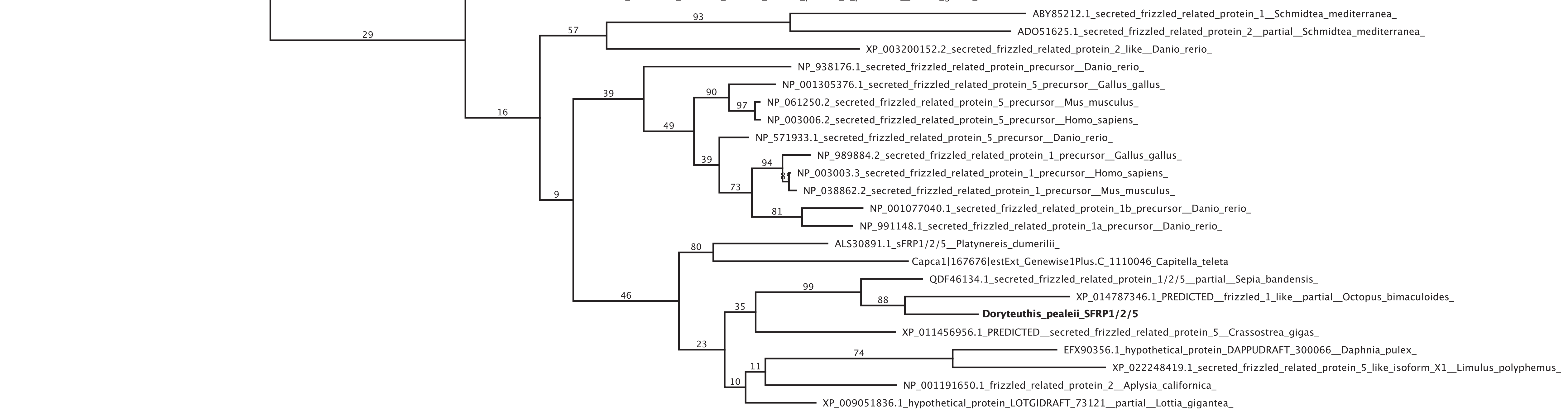

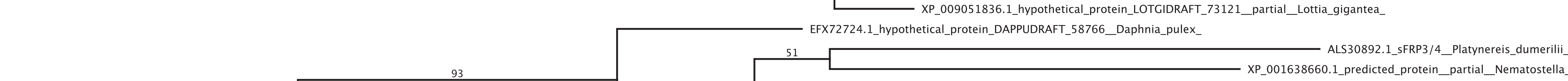
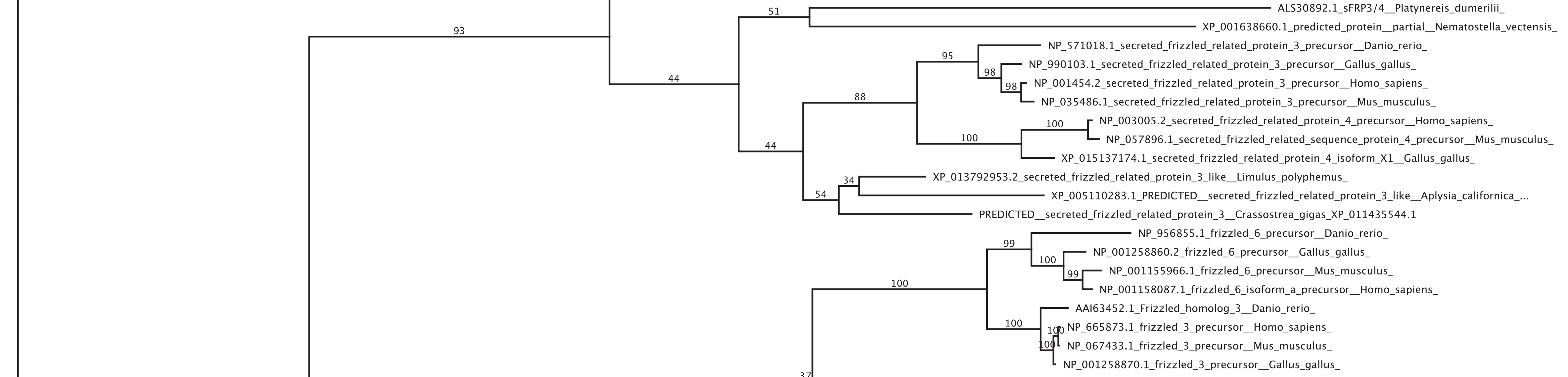

NP_001258770.__frizzled____precursor_Gallus_allus_

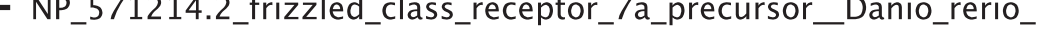

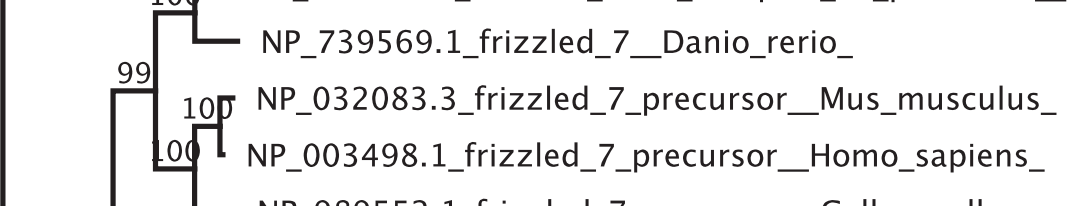

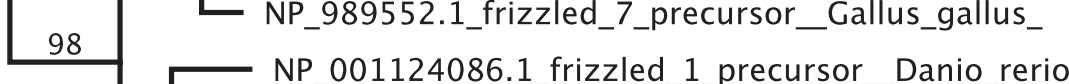

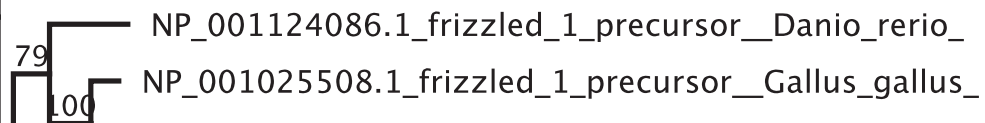

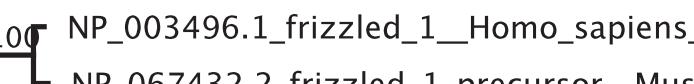

(1)

NP_.989553.1 frizzled_2_precursor_Callus_gallus -

op NP_001457.1_frizzled____precursor_Homo__aniens-

NP_065256.1_frizzled___precursor_Mus_musculus_

CXP_013788951.1_frizzled_1 like_Limulus polyphemus_

99 - XP_0137849922.1_frizzled___like_Limulus_polyphemus_-

86 N__001164247.1_frizzled_precursor_Tribolium_castaneum_

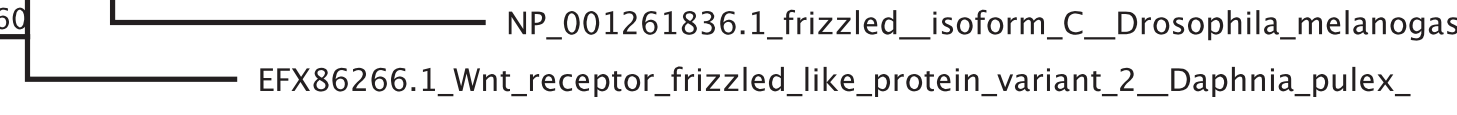

ELT94235.1_hypothetical_protein_CAPTEDRAFT_101526_partial_Capitella_teleta_

30 ALS30887.__frizzled 1/2/7_Platynereis_dumerilii_

100 - Doryteuthis_pealeii_frizzled_1/2/7

XP 009047666 . 1 hypothetical protein_LTG_Coctopus_bimaculoides_

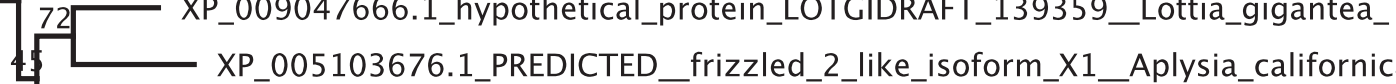

XP_001647502012323839.1_frizzled_2_like_Crassostrea_virginica_

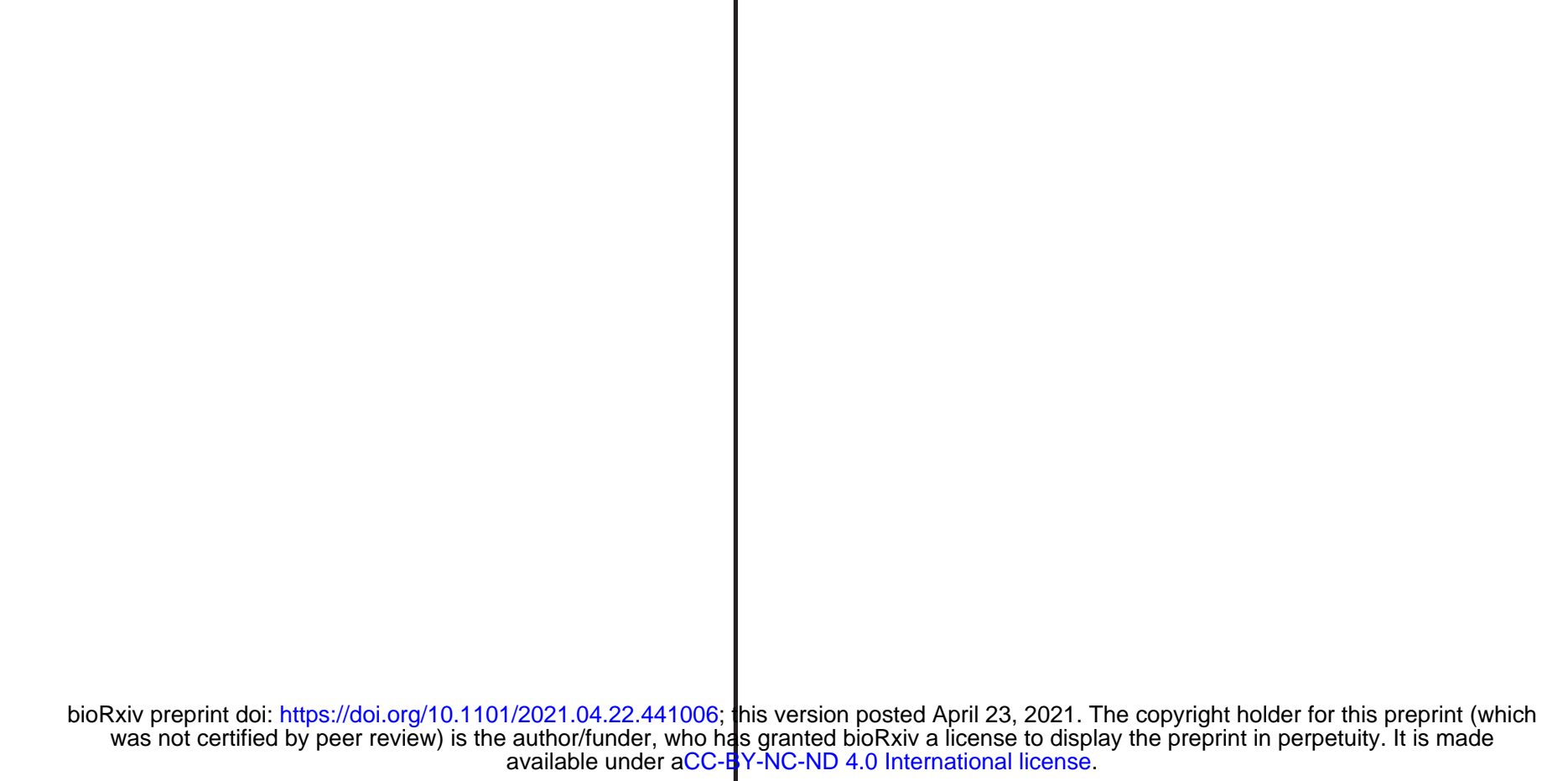


_XP_001627502.2_cyclin-dependent_kinase-like_2_[Nematostella_vectensis]

100

XP 002735020.2 PREDICTED: cyclin-dependent kinase-like 2-like, partial Saccoglossus kowalevskii was not certififaen

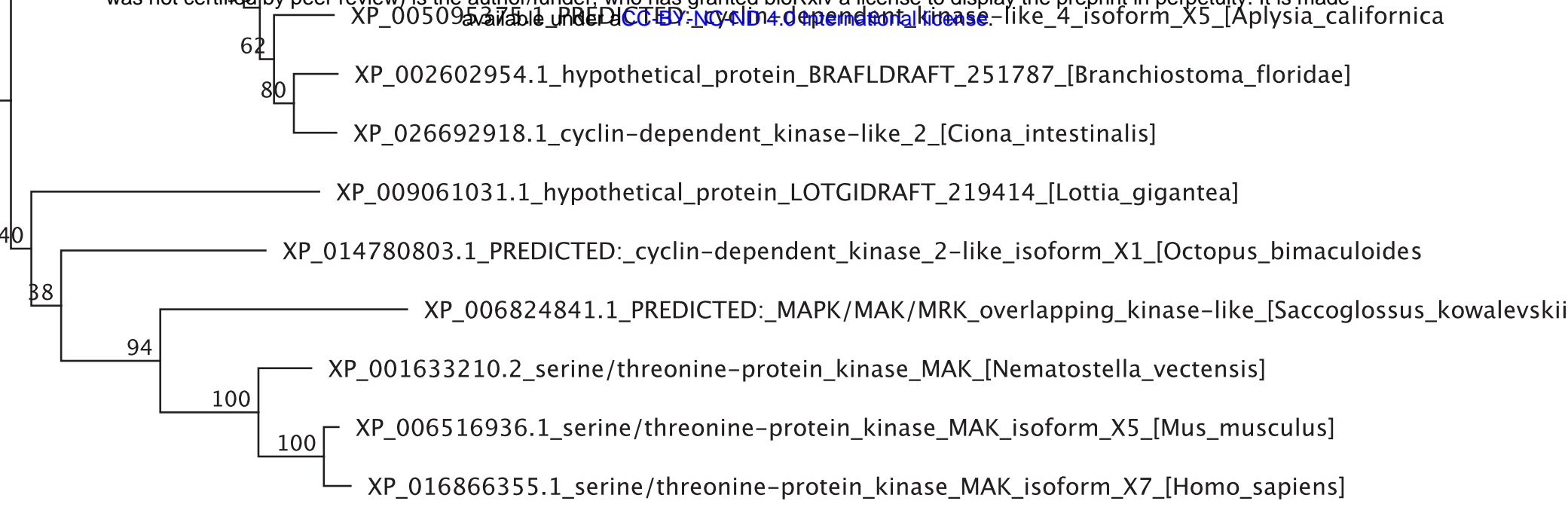

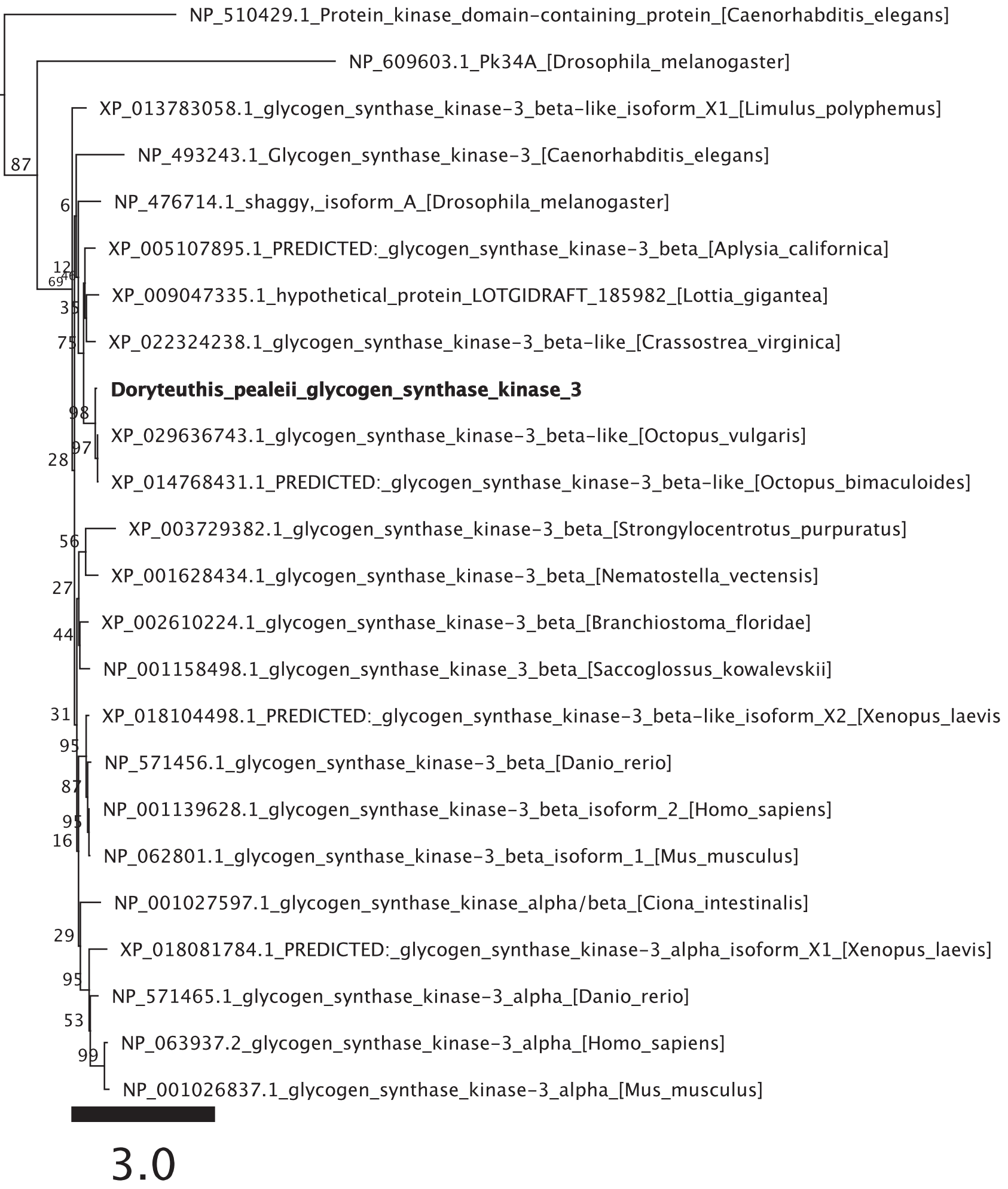


BAQ19232.1_Lhx6/8_LIM_homeobox_protein_partial_Lottia_gigantea_

g1 NP_523907.2_arrowhead_isoform_A_Drosophila_melanogaster_

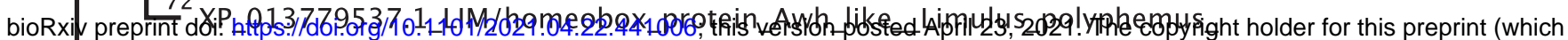

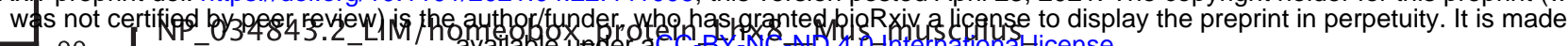
99

35NP_001003980.1_LIM/homeobox_protein_Lhx8_Danio_rerio_

9929P_001035556.2_LIM/homeobox_protein_Lhx8_Gallus_gallus_

[ NP_001004015.1_LIM/homeobox_protein_Lhx6_Danio_rerio_

P5XP_015135323.1_LIM/homeobox_protein_Lhx6_isoform_X1_Gallus_gallus

96P_032526.2_LIM/homeobox_protein_Lhx6_isoform_1_Mus_musculus_

97__001229263.1_LIM/homeobox_protein_Lhx6_isoform_4_Homo_sapiens_

BAQ19231.1_Lhx2/9_LIM_homeobox_protein_partial_Lottia_gigantea_

XP_014781050.1_PREDICTED_LIM/homeobox_protein_Lhx9_like_isoform_X1_Octopus_bimaculoides

NP_001163058.1_apterous_isoform_C_Drosophila_melanogaster_

XP_013780892.1_LIM/homeobox_protein_Lhx9_like_Limulus_polyphemus_

NP_001035099.3_LIM/homeobox_protein_Lhx2_Danio_rerio_

XPP_015134812.2_LIM/homeobox_protein_Lhx2_isoform_X1_Gallus_gallus_

8ج__006497796.1_LIM/homeobox_protein_Lhx2_isoform_X1_Mus_musculus_

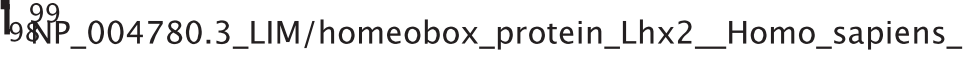

NP_001032320.2_LIM/homeobox_protein_Lhx9_isoform_2_Danio_rerio_

XXP_015145736.1_LIM/homeobox_protein_Lhx9_isoform_X1_Gallus_gallus_

PSP_001036042.1_LIM/homeobox_protein_Lhx9_isoform_c_Mus_musculus_

N9_064589.2_LIM/homeobox_protein_Lhx9_isoform_1_Homo_sapiens_

XP_013794263.1_LIM/homeobox_protein_Lhx3_like_isoform_X2_Limulus_polyphemus_

54 NP_476606.1_Lim3_isoform_A_Drosophila_melanogaster_

XP_014791107.1_PREDICTED_LIM/homeobox_protein_Lhx3_like_partial_Octopus_bimaculoides

g93

BAQ19230.1_Lhx3/4_LIM_homeobox_protein_partial_Lottia_gigantea_

NP_001116445.1_LIM/homeobox_protein_Lhx4_Danio_rerio_

1XP_025009019.1_LIM/homeobox_protein_Lhx4_isoform_X1_Gallus_gallus_

Ap_034842.2_LIM/homeobox_protein_Lhx4_Mus_musculus_

${ }_{96} \mathrm{~N}^{\mathrm{P}}$ _203129.1_LIM/homeobox_protein_Lhx4_Homo_sapiens_

[ NP_001034742.1_LIM/homeobox_protein_Lhx3_isoform_a_Mus_musculus_

[ 98 PP_835258.1_LIM/homeobox_protein_Lhx3_isoform_a_Homo_sapiens_

7 N8_571283.1_LIM/homeobox_protein_Lhx3_Danio_rerio_

W9_001025506.1_LIM/homeobox_protein_Lhx3_Gallus_gallus_

[ NP_571291.1_LIM/homeobox_protein_Lhx1_Danio_rerio_

99P_990744.1_LIM/homeobox_protein_Lhx1_Gallus_gallus_

P\$P_032524.1_LIM/homeobox_protein_Lhx1_Mus_musculus_

67.

NP_571293.1_LIM/homeobox_protein_Lhx5_Danio_rerio_

3》P_001307835.1_LIM/homeobox_protein_Lhx5_Gallus_gallus_

4JP_032525.1_LIM/homeobox_protein_Lhx5_Mus_musculus_

12 XP_014778793.1_PREDICTED_LIM/homeobox_protein_Lhx1_like_Octopus_bimaculoides_

3̂P_071758.1_LIM/homeobox_protein_Lhx5_Homo_sapiens_

XP_022239095.1_LIM/homeobox_protein_Lhx5_like_isoform_X1_Limulus_polyphemus_

XP_011450364.1_PREDICTED_LIM/homeobox_protein_LhX5_Crassostrea_gigas_

75 Doryteuthis_peallii_Lhx1/5

$4 \frac{47}{69}$ XP_012946044.1_PREDICTED_LIM/homeobox_protein_Lhx5_like_partial_Aplysia_californica_

10 BAQ19229.1_Lhx1/5_LIM_homeobox_protein_partial_Lottia_gigantea_

ADG26732.1_Lhx1/5_partial_Platynereis_dumerilii_

ELU00131.1_hypothetical_protein_CAPTEDRAFT_168913_Capitella_teleta_

EFX66374.1_hypothetical_protein_DAPPUDRAFT_11288_partial_Daphnia_pulex_

NP_572505.1_LIM_homeobox_1_isoform_A_Drosophila_melanogaster_

${ }^{84}$ XP_008194940.1_PREDICTED_LIM/homeobox_protein_Lhx5_isoform_X2_Tribolium_castaneum_ 
(2) was not certified by peer review) is the author/funder, who has granted bioRxiv a license to display the preprint in perpetuity. It is made

100

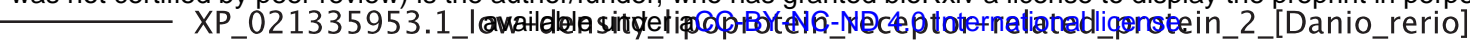
100

_NP_001181916.1_low-density_lipoprotein_receptor-related_protein_2a_precursor_[Danio_rerio

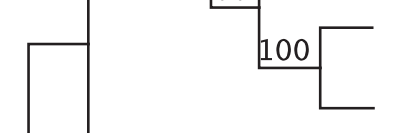

NP_001074557.1_low-density_lipoprotein_receptor-related_protein_2_precursor_[Mus_musculus

XP_011509486.1_low-density_lipoprotein_receptor-related_protein_2_isoform_X2_[Homo_sapiens

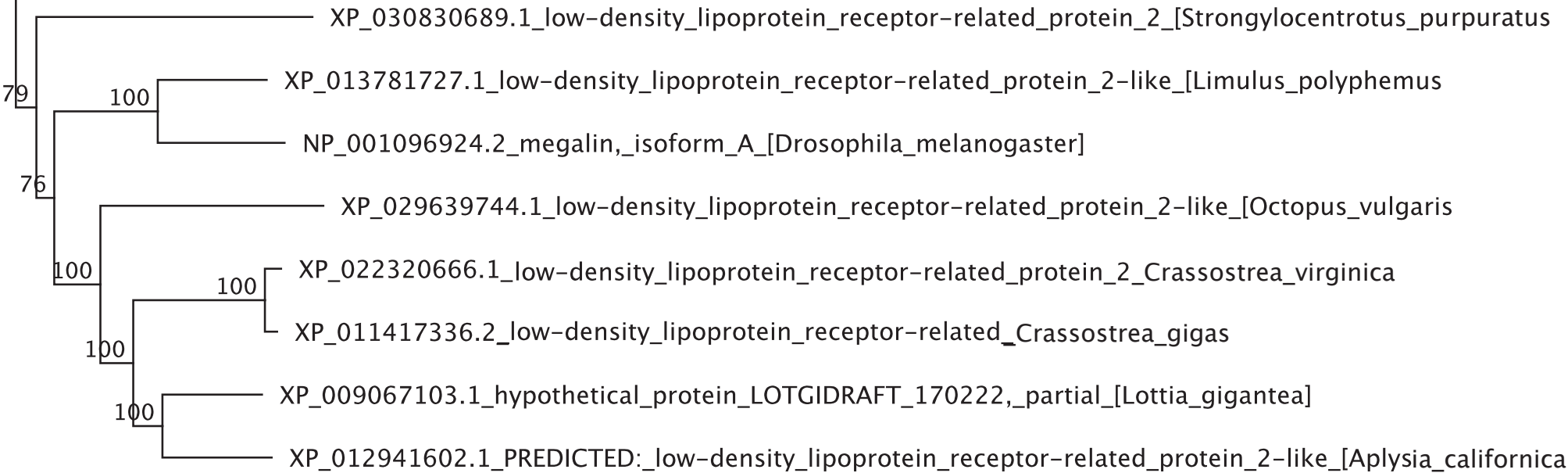

XP_032222949.1_low-density_lipoprotein_receptor-related_protein_1_[Nematostella_vectensis

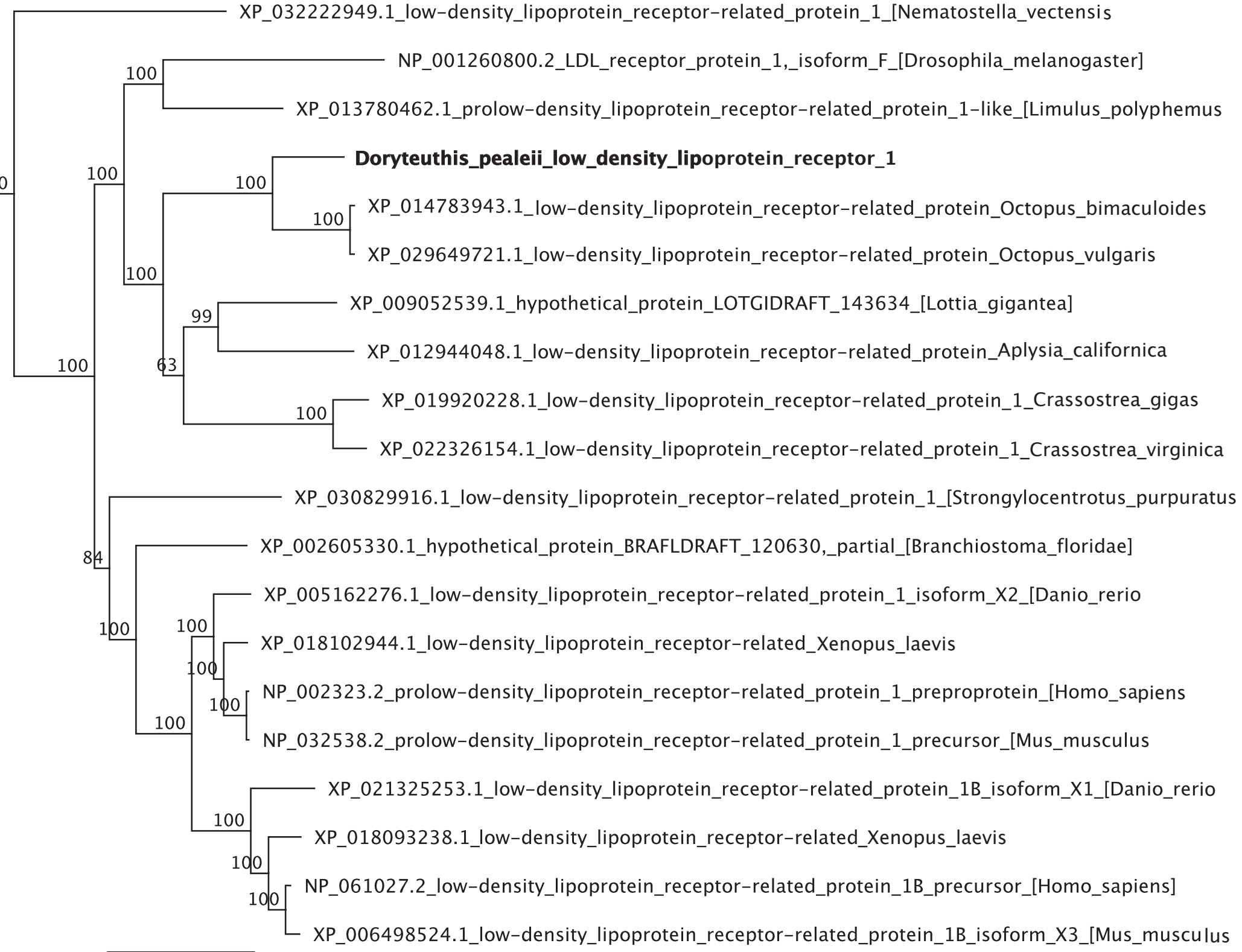


XP_015154642.2_homeobox_protein_aristaless_like_3_Gallus_gallus_
XP 695330.1 homeobox protein_aristaless_like_3 isoform_X2__Danio_rerio_

81 NP_006483.2_homeobox_protein_aristaless_like_3_Homo_sapiens

NPA_031467.1_homeobox_protein_aristaless_like_3_Mus_musculus_

70 NP 001038539.1_ALX_homeobox_protein_1_Danio_rerio_

ק9NP_0008913.2_ALX_homeobox_protein_1_Homo_sapiens

7XP_025010336.1_ALX_homeobox_protein_1_Gallus_gallus

44 [ $\beta_{P}{ }_{2}$ 766141.1_ALX_homeobox_protein 1 Mus_musculus

NP 001297007.1 aristaless_like_homeobox_4_Danio_rerio

99 XP_001340966.1_homeobox_protein_aristaless_like_4_-Danio_rerio

73 4

[NP_068745.2_homeobox_protein_aristaless_like_4_Homo_sapiens

_ KOF68148.1_hypothetical_protein_OCBIM_22007999mg_OCtopus_bimaculoides

ADB22393.1aristalesshomeodomaintranscriptionfactor Saccoglossuskowalevskii

APD 001164685.1 aristaless homeodomain transcription factor_Saccoglossus kowalevskii

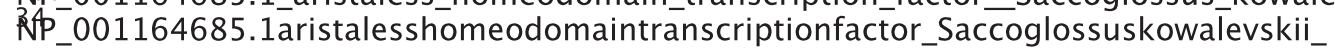

- ELU05130.1_hypothetical_protein_CAPTEDRAFT_70691_partial_Capitella_teleta_

70-XP_009057606.1_hypothetical_protein_LOTGIDRAFT_78457_partial_Lottia_gigantea_

XP__022292539.1_ALX_homeobox_protein_1__like_Crassostrea_virginica_-

${ }_{X} \mathrm{P}_{\mathrm{P}}$ 022088377.1retinalhomeoboxproteinRx_likeisoformX1_Acanthasterplanci

XP_011661786.1PREDICTED_ALXhomeoboxprotein1_Strongylocentrotuspurpuratus_

AEK64851.1_aristaless_like_homeobox_protein_Branchiostoma_floridae_

AQEK64850.1aristaless_likehomeoboxprotein_Branchiostomafloridae_

XP_022088259.1ALXhomeoboxprotein1_likeisoformX1_Acanthasterplanci_

XP_011661779.1PREDICTED_aristaless_likehomeoboxproteinisoformX2_Strongylocentrotuspurpuratus NP_999809.1_aristaless_like_homeobox_protein_Strongylocentrotus_purpuratus

XP 796340.1PREDICTED retinalhomeoboxproteinRx1 Strongylocentrotuspurpuratus AAF89581.1paired_boxtranscriptionfactor_Branchiostomafloridae.

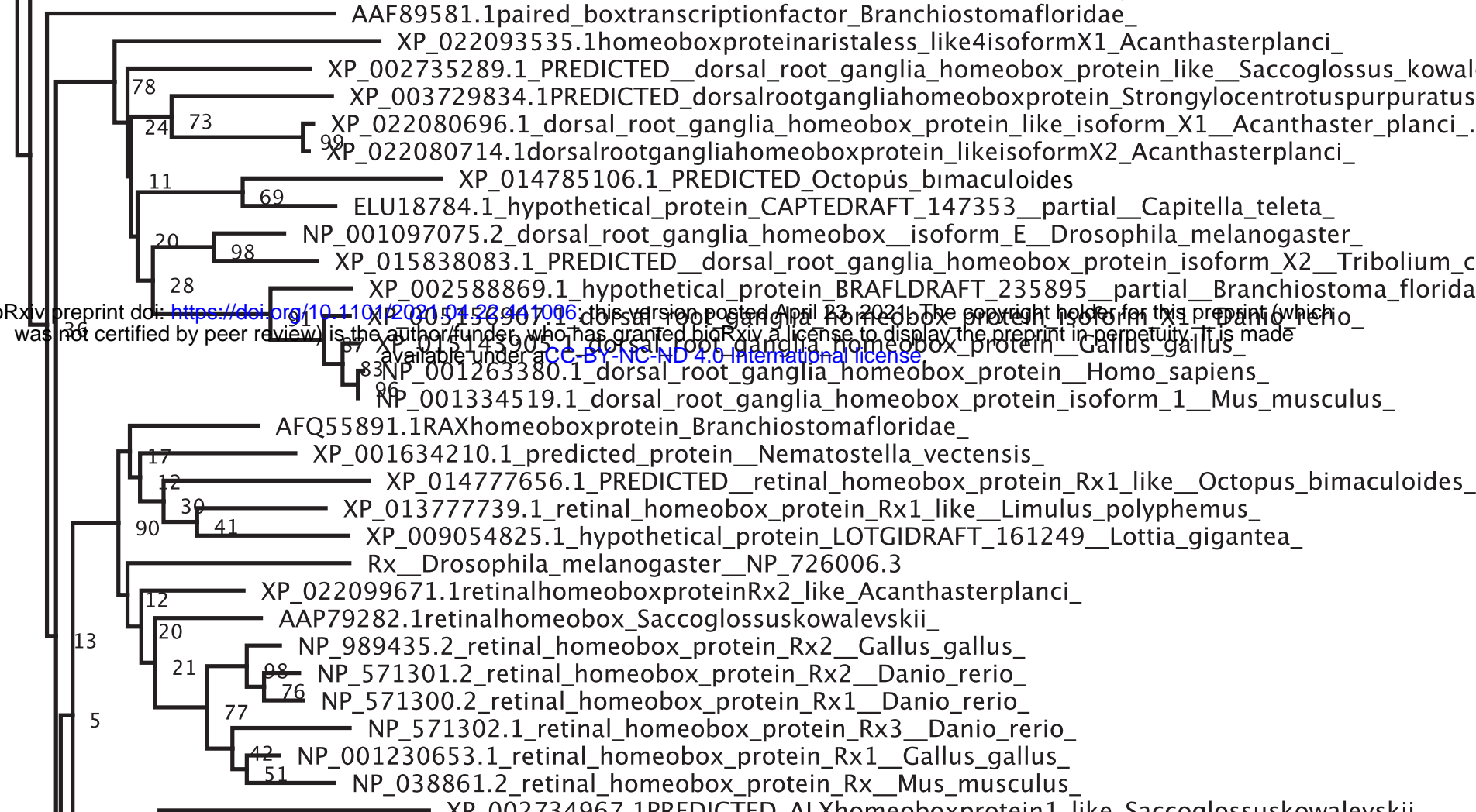

_XP_002734967.1PREDICTED_ALXhomeoboxprotein1_like_Saccoglossuskowalevskii_ XP_022303815.1_homeobox_protein_aristaless_like_Crassostrea_virginica_ XP_002608190.1retinalhomeoboxprotein_likeprotein_Branchiostomafloridae

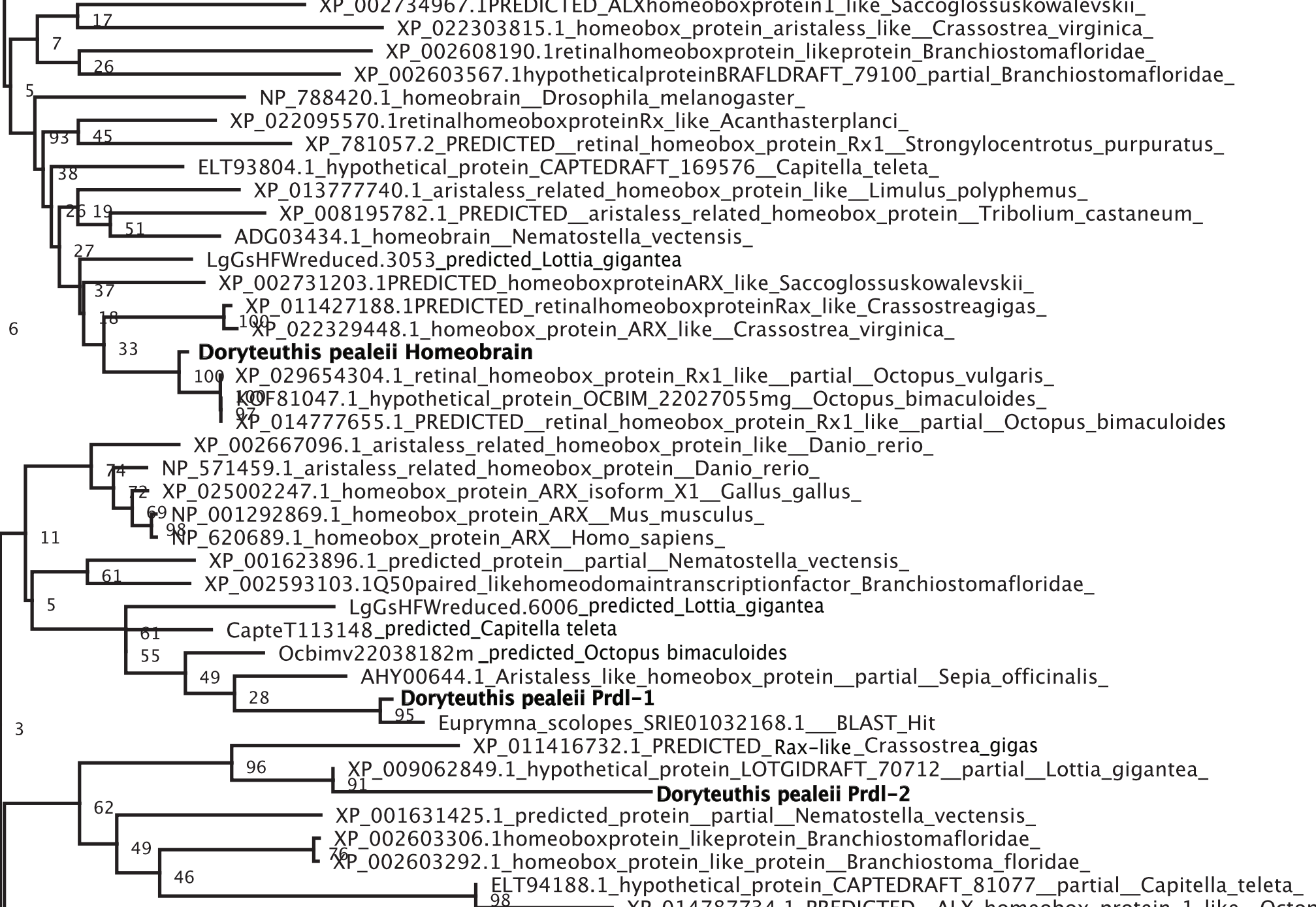

ELT94188.1_hypothetical_protein_CAPTEDRAFT_81077_partial_Capitella_teleta

2 XP 022101934.1LOWQUALITYPROTEIN _ aristaless_relatedhomeoboxprotein like_Acanthasterplanci...Ttopus_bimaculoides_

$63[\mathrm{sp|Q} 26 \overline{6} 57.2$ |ALX_STRPURecName_Full=Aristalesshomeoboxprotein_Strongylocentrotus_purpuratus

\$9P_011677119.1PREDICTED_aristalesshomeoboxprotein_Strongylocentrotuspurpuratus_.

11 XP_013782258.1_homeobox_protein_ARX_like_isoform_X2_Limulus_polyphemus_
XP_013786450.1_homeobox_protein_ARX_like_isoform_X2_Limulus_polyphemus_-
45 NP_722629.1_aristaless_Drosophila_melanogaster_-

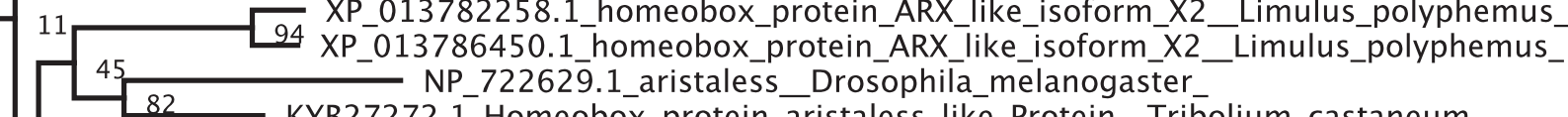

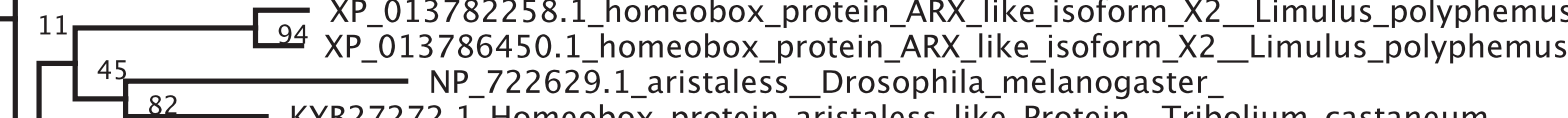

$18 \quad[92 \times P$ P 011423594.1 .1PREDICTED homeobox_protein_aristaless Crassostrea_gigas

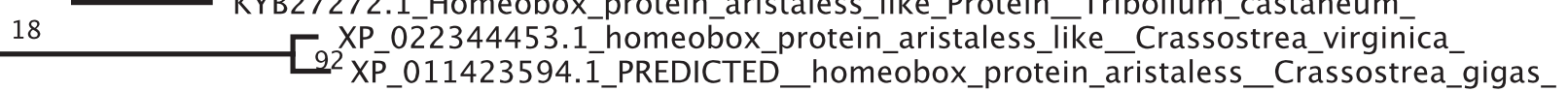

9 XP_009063369.1_hypothetical_protein_LOTGIDRAFT_78925_partial_Lottia_gigantea_-

11 XP_014788942.1_PREDICTED_aristaless_related_homeobox_protein_like_Octopus_bimaculoides

ZX_029648014.1_aristaless_ripredicted_Capitella teleta

ataless_related_homeobox_protein_like_Octopus_vulgaris_ 
AAH75739.1_Meis3_protein_Danio_rerio_

92 5757853.1_homeobox_protein_Meis3_Danio_rerio_

- AAH65977.1_Meis4.1a_protein_Danio_rerio_

NP_571968.1_homeobox_protein_Meis1_Danio_rerio_

XP_015133525.1_homeobox_protein_Meis1_isoform_X1_Gallus_gallus_

- XP_011441096.1_PREDICTED_homeobox_protein_Meis1_isoform_X2_Crassostrea_gigas_

XP_014785942.1_PREDICTED_homeobox_protein_Meis1_like_isoform_X3_Octopus_bimaculoides_

49 [O 00 Doryteuthis pealeii_Meis

48 XP_009057308.1_hypothetical_protein_LOTGIDRAFT_121570_partial_Lottia_gigantea_

d[ 7 XP_012940532.1_PREDICTED_homeobox_protein_Meis1_like_Aplysia_californica_

I_ AMZ00044.1_transcription_factor_homothorax_partial_Platynereis_dumerilii_

321693

33 ELT94055.1_hypothetical_protein_CAPTEDRAFT_139538_partial_Capitella_teleta

[XP_022237651.1_homeobox_protein_homothorax_like_isoform_X1_Limulus_polyphemus_

71EFX75948.1_putative_transcriptional_factor_Homothorax_protein_Daphnia_pulex_

24 [XP_015837042.1_PREDICTED_homothorax_isoform_X3_Tribolium_castaneum_

51 49 AAC47759.1_homothorax_Drosophila_melanogaster_

XP_024305695.1_homeobox_protein_Meis2_isoform_X3_Homo_sapiens_

N99_034955.1_homeobox_protein_Meis2_isoform_2_Mus_musculus_

100

Z8_025006330.1_homeobox_protein_Meis2_isoform_X5_Gallus_gallus_

3QXP_009292852.1_meis_homeobox_2b_isoform_X1_Danio_rerio_

Q XP_009291615.1_homeobox_protein_Meis2_isoform_X1_Danio_rerio_

NP_034919.1_homeobox_protein_Meis1_isoform_A_Mus_musculus_

NP_002389.1_homeobox_protein_Meis1_Homo_sapiens_

NP_001333077.1_homeobox_protein_Meis3_isoform_4_Homo_sapiens_

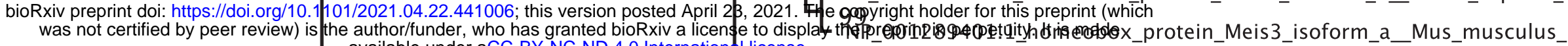

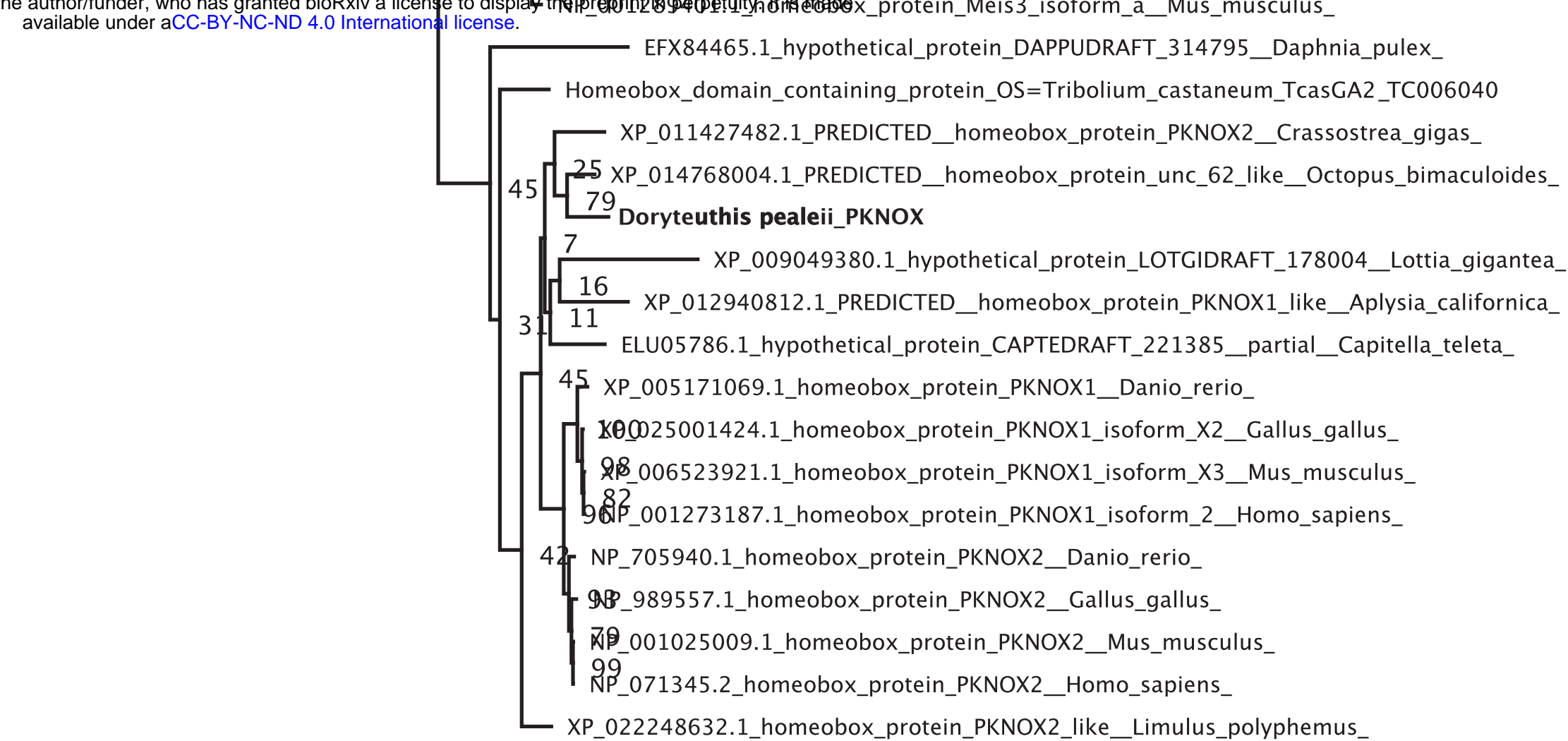

NP_001278438.1_pre_B_cell_leukemia_transcription_factor_1_isoform_d_Mus_musculus_

[ XP_016856884.1_pre_B_cell_leukemia_transcription_factor_1_isoform_X4_Homo_sapiens_

UDF46130.1_extradenticle_partial_Sepia_officinalis_

5x_014777430.1_PREDICTED_Pbx_Octopus_bimaculoides

27 Doryteuthis pealeii_Pbx

72P_011452237.1_PREDICTED_Pbx_Crassostrea_gigas

\$2_009044535.1_hypothetical_protein_LOTGIDRAFT_92730_partial_Lottia_gigantea_

- AMZ00043.1_transcription_factor_extradenticle_partial_Platynereis_dumerilii_

XP_013791623.1_homeobox_protein_extradenticle_like_Limulus_polyphemus

386P_001034501.1_extradenticle_Tribolium_castaneum_

L9PP_001259592.1_extradenticle_isoform_D_Drosophila_melanogaster

NP_571522.1_pre_B_cell_leukemia_transcription_factor_4_Danio_rerio_

XP_015145727.1_pre_B_cell_leukemia_transcription_factor_1_isoform_X3_Gallus_gallus_

[XP_423764.1_pre_B_cell_leukemia_transcription_factor_4_Gallus_gallus_

74NP_001020125.1_pre_B_cell_leukemia_transcription_factor_4_isoform_1_Mus_musculus_

Z28NP_079521.1_pre_B_cell_leukemia_transcription_factor_4_Homo_sapiens_

32NP_571687.1_pre_B_cell_leukemia_homeobox_2_Danio_rerio_

NP_059491.1_pre_B_cell_leukemia_transcription_factor_2_Mus_musculus_

1 108_02577.2_pre_B_cell_leukemia_transcription_factor_2_Homo_sapiens_

7NP_001277505.1_pre_B_cell_leukemia_transcription_factor_3_isoform_PBX3b_Mus_musculus_

6\$_571691.1_pre_B_cell_leukemia_transcription_factor_3_isoform_2_Danio_rerio_

_025011808.1_pre_B_cell_leukemia_transcription_factor_3_isoform_X2_Gallus_gallus_

NP_006186.1_pre_B_cell_leukemia_transcription_factor_3_isoform_1_Homo_sapiens_

NP_001077322.2_pre_B_cell_leukemia_homeobox_1_Danio_rerio_ 
NP_491053.4_Protein_pop_1_Caenorhabditis_elegans_

XP_022256844.1_transcription_factor_Sox_5_like_isoform_X2_Limulus_polyphemus_

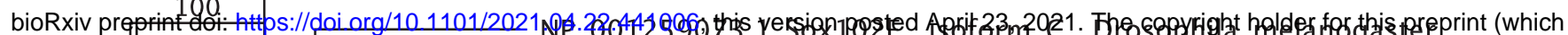
was not certified by ser review) is the authorffunder, who has granted biokxiva license to display the preprint in perpetuity. It is made

100 100

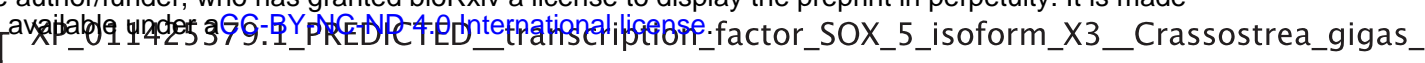

L XP_022302944.1_transcription_factor_Sox_5_like_isoform_X3_Crassostrea_virginica_

$$
\begin{aligned}
& 100 \quad \text { NP_001076773.1_HMG_box_domain_containing_protein_Caenorhabditis_elegans_ } \\
& \text { 100 XP_003200581.2_protein_capicua_homolog_isoform_X1_Danio_rerio_ } \\
& 32100100 \text { XP_018081794.1_PREDICTED_protein_capicua_homolog_isoform_X5_Xenopus_laevis_ } \\
& 55 \text { [XP_011524969.1_protein_capicua_homolog_isoform_X10_Homo_sapiens_ } \\
& 90 \text { XP_002740950.1_PREDICTED_protein_capicua_homolog_Saccoglossus_kowalevskii_ } \\
& \text { XP_029647832.1_protein_capicua_homolog_isoform_X3_Octopus_vulgaris_ }
\end{aligned}
$$

XP_002596146.1_hypothetical_protein_BRAFLDRAFT_66125_Branchiostoma_floridae _

NP_001071831.1_transcription_factor_protein_Ciona_intestinalis_ 

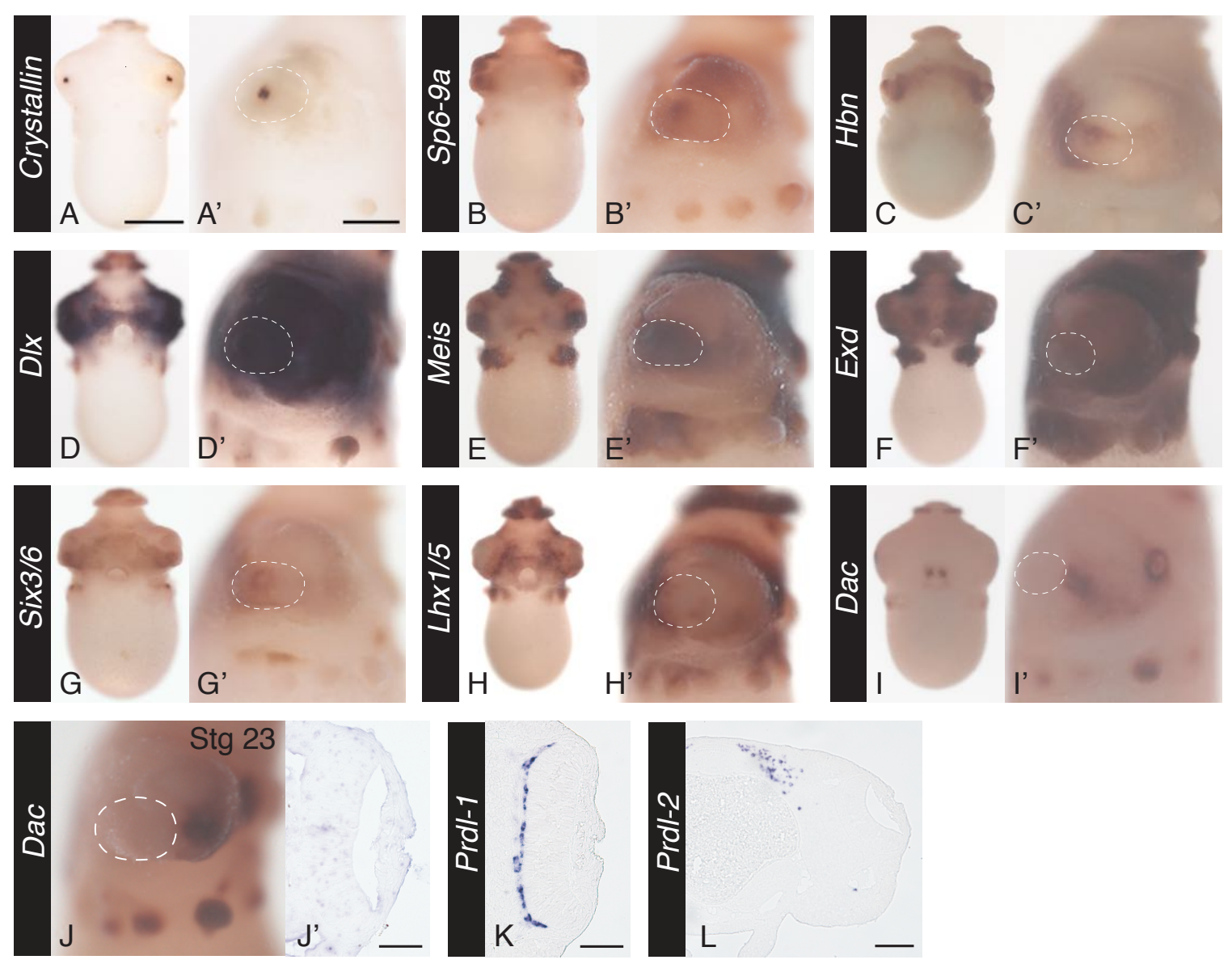

673

\section{Sup Figure 2: Limb network supplemental data}

A-I) Gene expression at stage 21 for limb network genes. For all genes from left to right, Anterior whole-mount and lateral whole-mount, anterior to the left. Scale for whole-mount anterior view is 500 microns. Scale for lateral whole-mount view 200 microns. J, J') Stage 23 Dac expression. J) Lateral whole mount, anterior to the left. J') Sectioned image of the eye. Anterior is down. K \& L) Sectioned image of expression of Prdl-1and Prdl-2. Scale is 50 microns on eye sections, 100 microns on brain section (Prdl-2) 

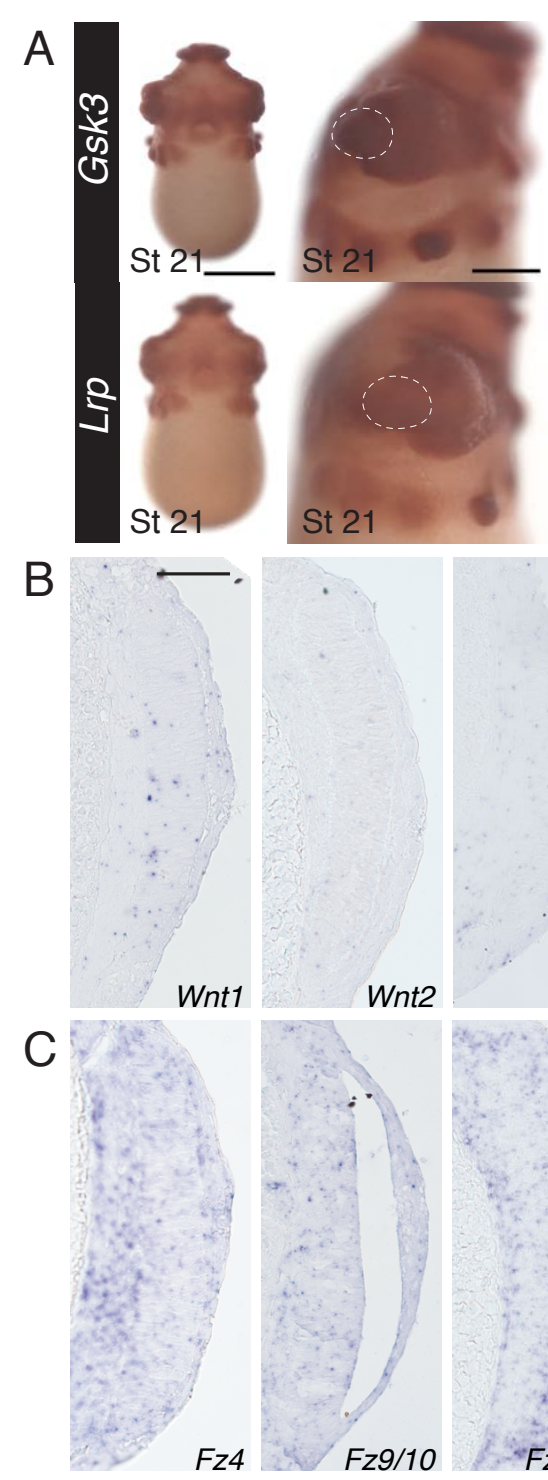

Wnt2
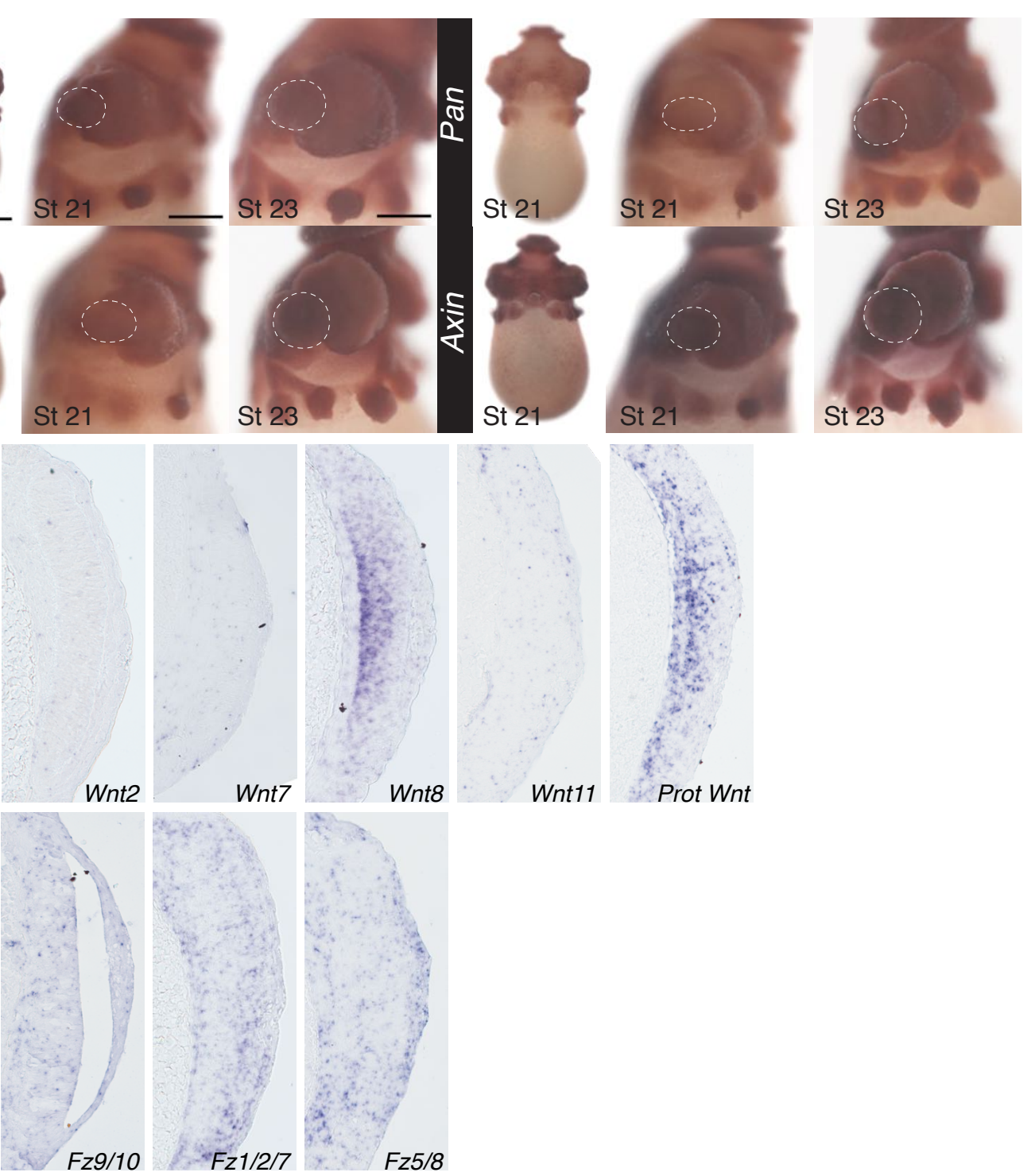

Wnt8

Wnt11

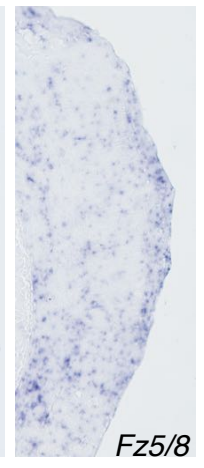

682

\section{Sup Figure 3: Wnt signaling expression supplemental data}

689
A) Wnt signaling pathway member expression, Gsk3, Lrp, Pan, and Axin, at stage 21 and 23 in whole-mount. Anterior view of stage 21 and lateral views of stage 21 and stage 23 (anterior to the left). B) Wnt gene expression at stage 21 in section. Anterior is down. C) Fz receptor gene expression at stage 21. Anterior is down. Scale for whole-mount anterior view is 500 microns. Scale for lateral whole-mount view 200 microns. Scale for sectioned images 50 microns. 
A

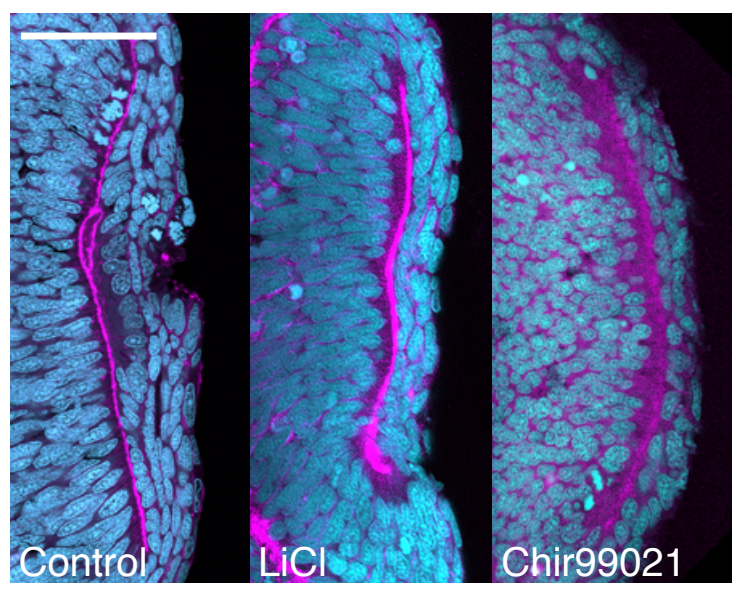

B

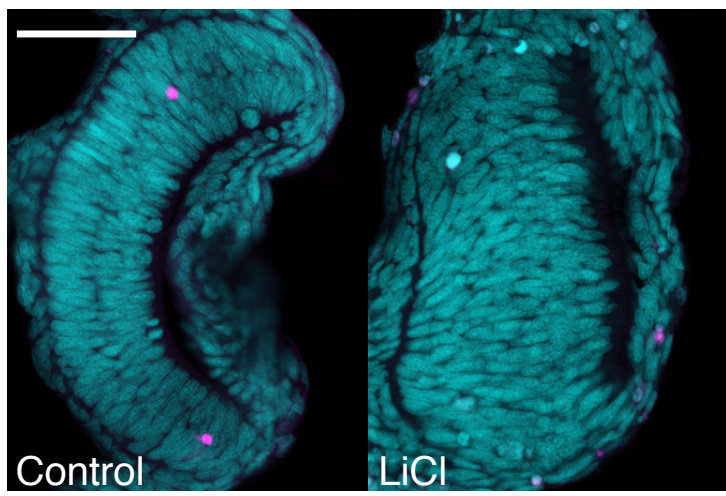

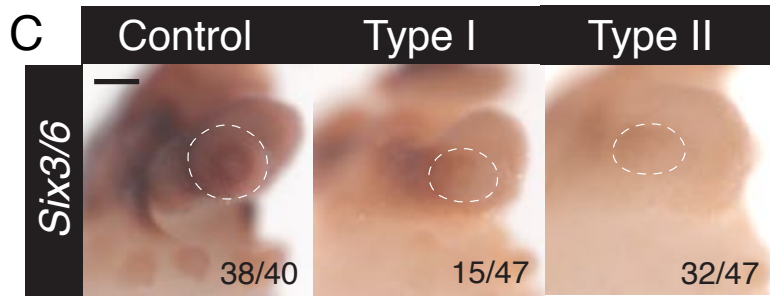
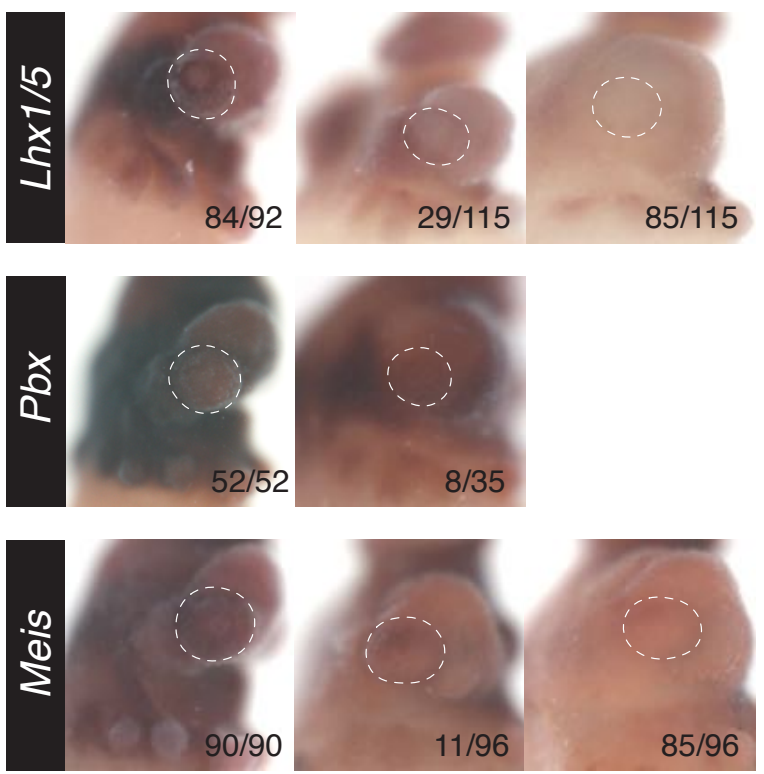

691 Sup Figure 4: Wnt agonist experiment supplemental data

692 A) Wnt agonist experiments starting at stage 21. Embryos were treated for 24 hours and fixed 693 immediately. $\mathrm{LiCl}$ and Chir99021 show similar phenotypes: Lack of anterior segment thickness 694 and loss of lens formation. Sytox nuclear stain in cyan, Phalloidin stain in magenta. Scale is 50 695 microns. B) Tunel staining of the eye of Control and $\mathrm{LiCl}$ treated embryos. Sytox nuclear stain in 696 cyan, Tunel stain in magenta. Similar amounts of cell death observed in control and treated 697 animals. Scale is 100 microns C) In situ hybridization of limb patterning program members and 698 and anterior segment markers after LiCl treatment. Type I (mild) and Type II (severe) phenotype. 699 White dotted line outlines the eye in the lateral image. Number of eyes scored in control and the 700 two phenotypes found in $\mathrm{LiCl}$ treated animals in the bottom right corner. Scale for lateral whole701 mount view 200 microns. 